NATIONAL LABORATORY

\title{
Design Study for a Low-Enriched Uranium Core for the High Flux Isotope Reactor, Annual Report for FY 2007
}

November 2007

Prepared by

R. T. Primm III

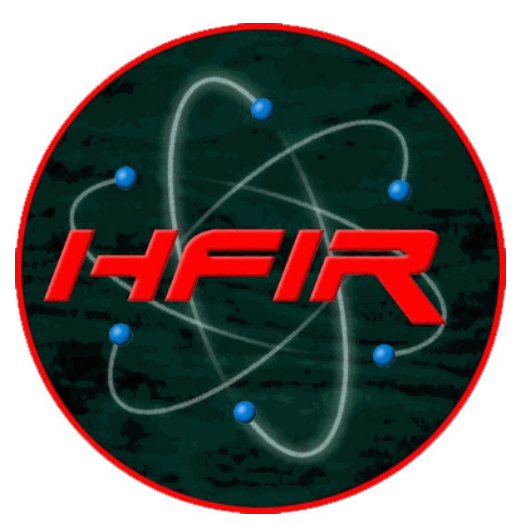

R. J. Ellis

J. C. Gehin

G. Ilas

J. H. Miller

J. D. Sease

C. Galvez Velit

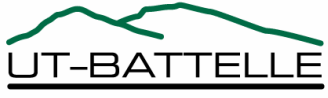




\title{
DOCUMENT AVAILABILITY
}

Reports produced after January 1, 1996, are generally available free via the U.S. Department of Energy (DOE) Information Bridge.

Web site http://www.osti.gov/bridge

Reports produced before January 1,1996 , may be purchased by members of the public from the following source.

\author{
National Technical Information Service \\ 5285 Port Royal Road \\ Springfield, VA 22161 \\ Telephone 703-605-6000 (1-800-553-6847) \\ TDD 703-487-4639 \\ Fax 703-605-6900 \\ E-mailinfo@ntis.fedworld.gov \\ Web site http://www.ntis.gov/support/ordernowabout.htm
}

Reports are available to DOE employees, DOE contractors, Energy Technology Data Exchange (ETDE) representatives, and International Nuclear Information System (INIS) representatives from the following source.

Office of Scientific and Technical Information

P.O. Box 62

Oak Ridge, TN 37831

Telephone 865-576-8401

Fax 865-576-5728

E-mail reports@osti.gov

Web site http://www.osti.gov/contact.html

This report was prepared as an account of work sponsored by an agency of the United States Government. Neither the United States government nor any agency thereof, nor any of their employees, makes any warranty, express or implied, or assumes any legal liability or responsibility for the accuracy, completeness, or usefulness of any information, apparatus, product, or process disclosed, or represents that its use would not infringe privately owned rights. Reference herein to any specific commercial product, process, or service by trade name, trademark, manufacturer, or otherwise, does not necessarily constitute or imply its endorsement, recommendation, or favoring by the United States Government or any agency thereof. The views and opinions of authors expressed herein do not necessarily state or reflect those of the United States Government or any agency thereof. 


\title{
DESIGN STUDY FOR A LOW-ENRICHED URANIUM CORE FOR THE HIGH FLUX ISOTOPE REACTOR, ANNUAL REPORT FOR FY 2007
}

\author{
R. T. Primm III \\ R. J. Ellis \\ J. C. Gehin \\ G. Ilas \\ J. H. Miller \\ J. D. Sease \\ Oak Ridge National Laboratory \\ C. Galvez Velit \\ University of California Berkeley
}

Date Published: November 2007

Prepared by

OAK RIDGE NATIONAL LABORATORY

Oak Ridge, Tennessee 37831-6283

managed by

UT-BATTELLE, LLC

for the

U.S. DEPARTMENT OF ENERGY

under contract DE-AC05-00OR22725 



\section{CONTENTS}

Page

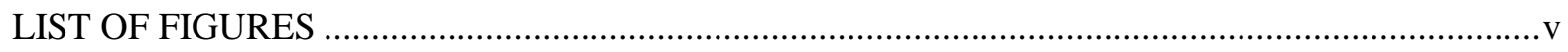

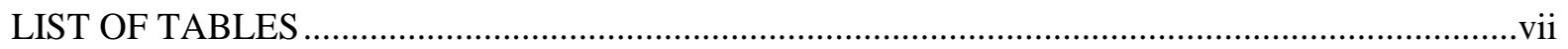

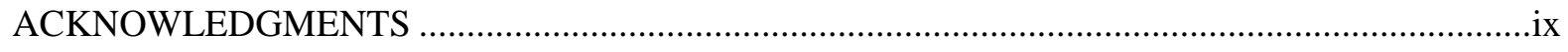

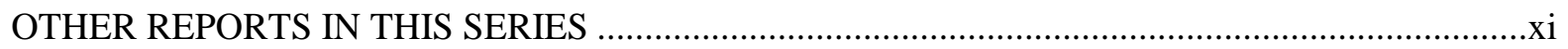

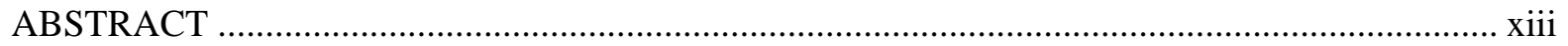

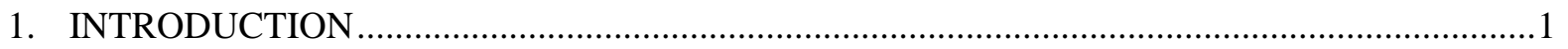

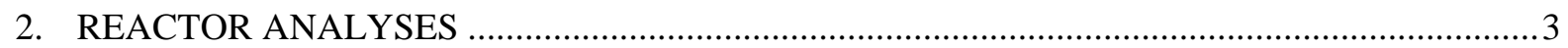

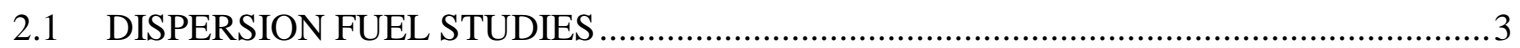

2.1.1 Design and Performance Parameters for a U-7Mo Fuel............................................. 3

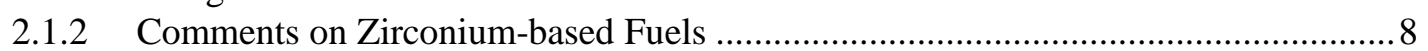

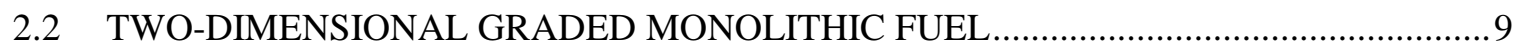

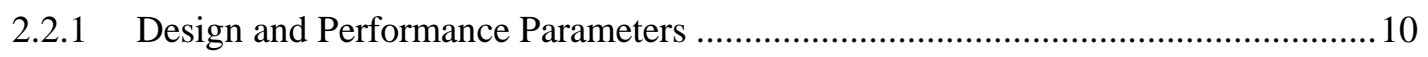

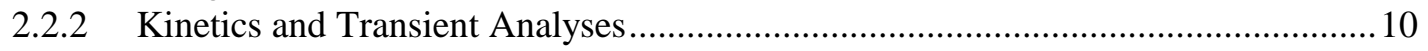

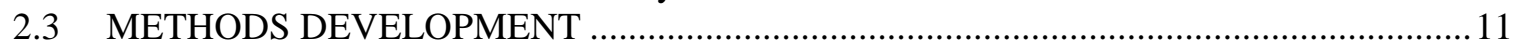

2.3.1 Multidimensional Cross Section Processing .........................................................

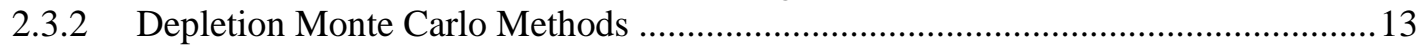

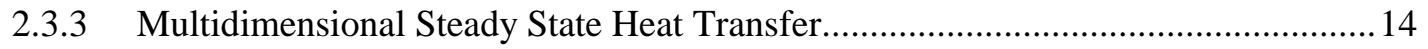

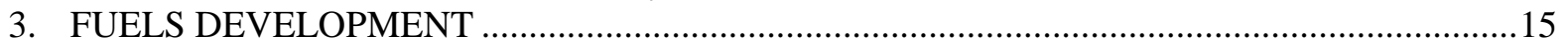

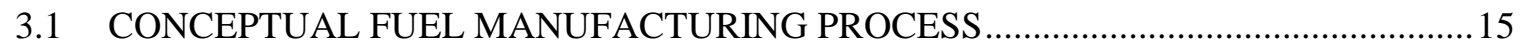

3.2 DEVELOPMENT OF A HFIR-SPECIFIC FUEL QUALIFICATION PLAN.....................15

3.2.1 Review of Possible U-Mo Foil Production and Cladding Processes.........................16

3.2.2 Preliminary Identification of HFIR-specific Fuel Qualification Tasks......................17

3.2.3 Graded Monolitic Foil—Preliminary Grinding Results ....................................... 18

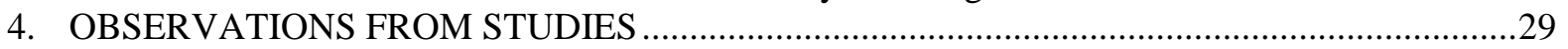

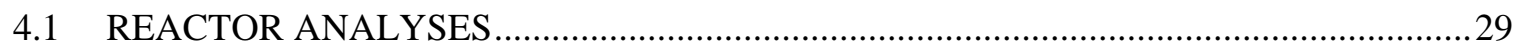

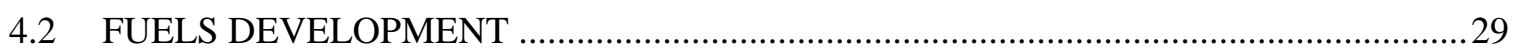

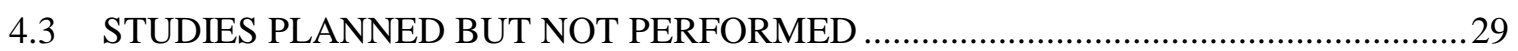

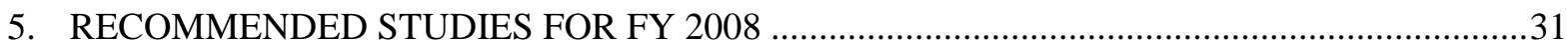

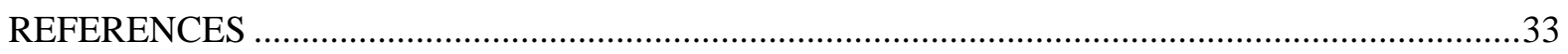

Appendix A. RATIO OF THERMAL FLUX, HEU-TO-LEU, AT HFIR COLD SOURCE

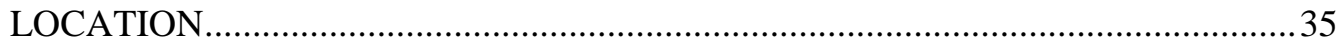





\section{LIST OF FIGURES}

Figure

Page

2.1 Comparison of $\mathrm{k}_{\mathrm{eff}}$ for U-7Mo dispersion LEU and current HEU HFIR cores...............5

2.2 Radial fast $(>0.1-\mathrm{MeV})$ and thermal $(<0.625-\mathrm{eV})$ neutron flux distributions in HFIR 6

2.3 Control element positions for the HEU and LEU simulations......................................

$2.4 \quad$ Effective multiplication factor $\left(\mathrm{k}_{\mathrm{eff}}\right)$ for LEU case showing that $\mathrm{k}_{\mathrm{eff}}$ was

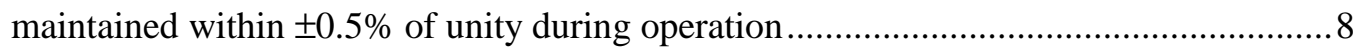

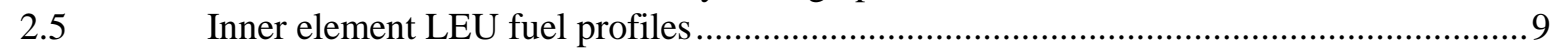

2.6 Outer element LEU fuel profiles ....................................................................

2.7 BOL power distribution for "only radial graded" fuel................................................ 10

2.8 2-D NEWT model of HFIR for broad group cross section generation .......................... 12

2.9 A 3-D MCNP simplified model of HFIR ….......................................................... 12

2.10 Comparison of macroscopic thermal fission cross section from MCNP

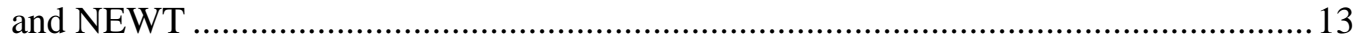

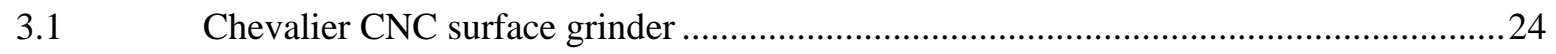

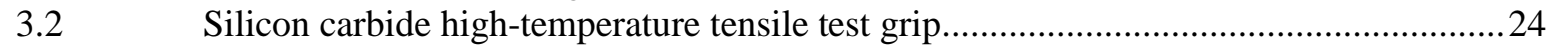

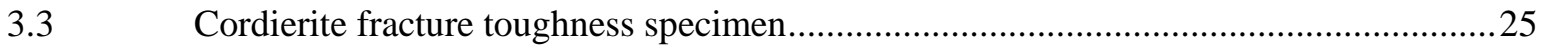

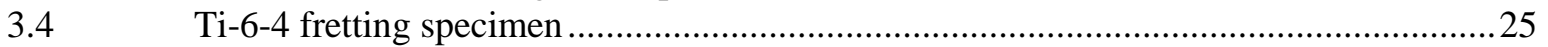

3.5 Example of the surrogate foil specimen after grinding .................................................26 



\section{LIST OF TABLES}

Table

Page

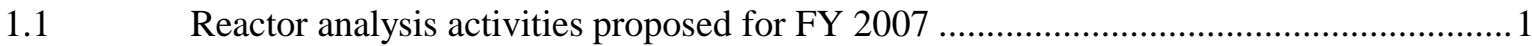

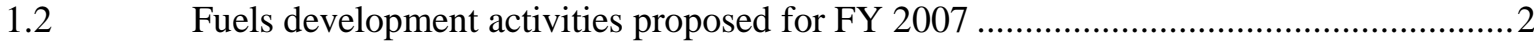

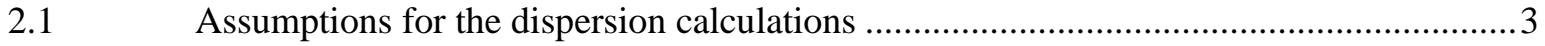

2.2 Operating conditions for FY 2006 U-10Mo dispersion fuel simulations ........................4

2.3 Uncoated LEU U-7Mo dispersion fuel profile and the current HEU fuel profile..............5

$2.4 \quad$ Thermal neutron flux results of the U-7Mo dispersion fuel core compared to the FY 2006, U-10Mo monolithic fuel core and the current HEU core ........................6

3.1 Tests to obtain data needed to qualify LEU fuel for HFIR ......................................... 19

3.2 Comparison of surface roughness data for ground and as-received surrogate

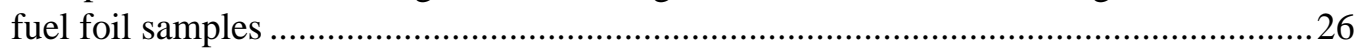

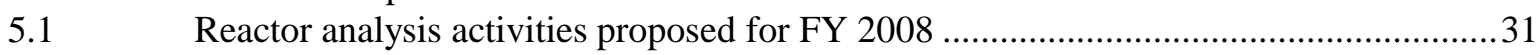

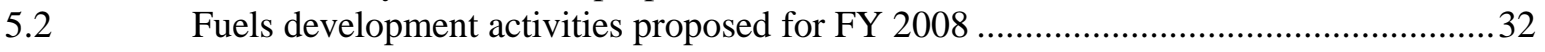

A.1 Thermal neutron fluxes at the HFIR cold source for an operating power of $85 \mathrm{MW}$ 



\section{ACKNOWLEDGMENTS}

The authors would like to acknowledge that the support for this project was provided by the Reduced Enrichment for Research and Test Reactors Program (RERTR), Nuclear National Security Administration, U.S. Department of Energy (DOE). The DOE program manager, Parrish Staples, Idaho National Laboratory RERTR fuels program manager, Daniel Wachs, and Argonne National Laboratory RERTR reactor analysis program manager, Jim Matos, all provided useful comments and reviews of this work during the fiscal year. The authors also acknowledge the technical reviews of this document preformed by K. A. Smith, Research Reactors Division, and Brian D. Murphy, Nuclear Science and Technology Division, Oak Ridge National Laboratory and thank all of the reviewers for their efforts and comments. Finally, the authors wish to thank Mary Wells, Brenda Smith, and Cynthia Southmayd for their excellence in document preparation and editing of this report. 



\section{OTHER REPORTS IN THIS SERIES}

R. T. Primm III, R. J. Ellis, J. C. Gehin, D. L. Moses, J. L. Binder, and N. Xoubi, Assumptions and Criteria for Performing a Feasibility Study of the Conversion of the High Flux Isotope Reactor Core to Use Low-Enriched Uranium Fuel, ORNL/TM-2005/269, February 2006.

R. T. Primm III, R. J. Ellis, J. C. Gehin, K. T. Clarno, K. A. Williams, and D. L. Moses, Design Study for a Low-Enriched Uranium Core for the High Flux Isotope Reactor, Annual Report for FY 2006, ORNL/TM-2006/136, November 2006.

J. D. Sease, R. T. Primm III, and J. H. Miller, Conceptual Process for the Manufacture of Lowenriched Uranium/Molybdenum Fuel for the High Flux Isotope Reactor, ORNL/TM-2007/39, September 2007.

C. Galvez Velit and R. T. Primm III, Partial Safety Analysis for a Reduced Uranium Enrichment Core for the High Flux Isotope Reactor, ORNL/TM-2007/226 (publication expected February 2008). 



\begin{abstract}
This report documents progress made during FY 2007 in studies of converting the High Flux Isotope Reactor (HFIR) from highly enriched uranium (HEU) fuel to low-enriched uranium (LEU) fuel. Conversion from HEU to LEU will require a change in fuel form from uranium oxide to a uranium-molybdenum alloy.

With an increase in reactor power to $100 \mathrm{MW}$, a high volume fraction U-Mo-in-Al fuel could attain the same neutron flux performance as with the current HEU fuel, but materials considerations appear to preclude production and irradiation of such a fuel. A diffusion barrier would be required if aluminum is to be retained as the interstitial medium, and the additional volume required for this barrier would degrade performance. Attaining the high volume fraction (55 wt \%) of U-Mo assumed in the computational study while maintaining the current fuel plate acceptance level at the fuel manufacturer is unlikely, that is, no increase in the percentage of plates rejected for noncompliance with the fuel specification. Substitution of a zirconium alloy for aluminum would significantly increase the weight of the fuel element, the cost of the fuel element, and introduce an as-yet untried manufacturing process.

A monolithic U-10Mo foil is the choice of LEU fuel for HFIR. Preliminary calculations indicate that with a modest increase in reactor power, the flux performance of the reactor can be maintained at the current level. A linearly graded, radial fuel thickness profile is preferred to the arched profile currently used in HEU fuel because the LEU fuel medium is a metal alloy foil rather than a powder. Developments in analysis capability and nuclear data processing techniques are under way with the goal of verifying the preliminary calculations of LEU flux performance.

A conceptual study of the operational cost of an LEU fuel fabrication facility yielded the conclusion that the annual fuel cost to the HFIR would increase significantly from the current HEU fuel cycle. Though manufacturing can be accomplished with existing technology, several engineering proof-of-principle tests would be required.

The RERTR program is currently conducting a series of generic fuel qualification tests at the Advanced Test Reactor. A review of these tests and a review of the safety basis for the current HEU fuel cycle led to the identification of a set of HFIR-specific fuel qualification tests. Much additional study is required to formulate a HFIR-specific fuel qualification plan from this set. However, one such test—creating a graded fuel profile across a flat foil—has been initiated with promising results.
\end{abstract}





\section{INTRODUCTION}

Design studies for a low-enriched uranium (LEU) core for the High Flux Isotope Reactor (HFIR) were conducted according to the plan documented in Refs. 1 and 2. Lists of the studies that had been planned for fiscal year (FY) 2007-published in Ref. 2-are shown in Tables 1.1 and 1.2. Those areas in which progress was made and documentation provided in this report are designated by shading. Discussion of tasks not conducted will also be presented in Sect. 4 of this report. Section 5 of this report is devoted to a discussion of tasks planned for FY 2008.

Table 1.1. Reactor analysis activities proposed for FY $2007^{2}$

\begin{tabular}{|c|c|c|}
\hline Area of study & Task ID & Subtask description \\
\hline \multirow{4}{*}{$\begin{array}{l}\text { One-dimensional (1-D) } \\
\text { graded fuels }\end{array}$} & \multirow[t]{3}{*}{ Monolithic } & Boron in aluminum end plate \\
\hline & & Transient analyses of reference design \\
\hline & & Determine maximum cycle fluence \\
\hline & Dispersion & $\begin{array}{l}\text { Increased volume fraction ( } 0.55) \text { for uncoated fuel } \\
\text { and change of fuel type to U-7Mo; include boron } \\
\text { in aluminum end plate if positive benefit }\end{array}$ \\
\hline $\begin{array}{l}\text { Two-dimensional } \\
\text { (2-D) graded fuels }\end{array}$ & Monolithic & $\begin{array}{l}\text { Develop grading profile } \\
\text { Transient analyses of reference design } \\
\text { Determine maximum cycle fluence }\end{array}$ \\
\hline $\begin{array}{l}\text { Economic/engineering } \\
\text { assessment }\end{array}$ & $\begin{array}{l}\text { Conversion to power } \\
>85 \mathrm{MW} \text {; both 1-D and } \\
\text { 2-D fuels as appropriate }\end{array}$ & $\begin{array}{l}\text { Similar study as Chap. } 4 \text { (Ref. 2) but identifies } \\
\text { cost/schedule for increasing HFIR power so } \\
\text { performance meets/exceeds current value }\end{array}$ \\
\hline \multirow[t]{7}{*}{$\begin{array}{c}\text { Methods/model } \\
\text { development }\end{array}$} & $\begin{array}{l}\text { Cross section processing and } \\
\text { deterministic methods } \\
\text { completion }\end{array}$ & $\begin{array}{l}\text { Develop/examine 2-D SCALE “slab" model } \\
\text { Documentation/archive VENTURE models } \\
\text { Transport methods (ATTILA }{ }^{3} \text { ) }\end{array}$ \\
\hline & \multirow{4}{*}{$\begin{array}{l}\text { Monte Carlo Neutron } \\
\text { Particle code (MCNP) } \\
\text { model development }\end{array}$} & Develop discrete plate representation model \\
\hline & & $\begin{array}{l}\text { Revise geometry to generate smaller volume zones } \\
\text { in fuel region }\end{array}$ \\
\hline & & $\begin{array}{l}\text { Update/make operational MCNP depletion model } \\
\left(\text { MONTEBURNS }{ }^{4}\right)\end{array}$ \\
\hline & & $\begin{array}{l}\text { Research publications for LEU validation; develop } \\
\text { plan for LEU validation studies }\end{array}$ \\
\hline & $\begin{array}{l}\text { Turbulent mixing, nonbond } \\
\text { assumptions in thermal- } \\
\text { hydraulic model }\end{array}$ & $\begin{array}{l}\text { Incorporate into HFIR steady state heat transfer } \\
\text { code; validate }\end{array}$ \\
\hline & $\begin{array}{l}\text { Probabilistic combination of } \\
\text { uncertainties }\end{array}$ & $\begin{array}{l}\text { Review/update TASHA code developed under } \\
\text { Advanced Neutron Source Program }\end{array}$ \\
\hline
\end{tabular}


Table 1.2. Fuels development activities proposed for FY $2007^{2}$

\begin{tabular}{|c|c|c|}
\hline \multicolumn{2}{|c|}{ Task name } & \multirow{2}{*}{$\begin{array}{l}\text { Start date or comment } \\
\text { Collaboration with FRM reactor } \\
\text { staff and FRM fuel fabricator } \\
\text { (CRCA/ARIVA) on physical } \\
\text { vapor deposition processes for } \\
\text { fabricating 2-D grading and } \\
\text { monolith diffusion barrier }\end{array}$} \\
\hline Graded fuel development program & & \\
\hline \multirow{3}{*}{$\begin{array}{l}\text { Diffractometry measurements-as } \\
\text { requested by RERTR program } \\
\text { (next HFIR cycle expected } \\
\text { December 2006; HFIR staff } \\
\text { recommend RERTR plan for } \\
\text { cycle after startup; March 2007) }\end{array}$} & $\begin{array}{l}\text { Sample preparation and } \\
\text { transportation inside ORNL }\end{array}$ & 3 months prior to HFIR startup \\
\hline & $\begin{array}{l}\text { Measurement preparation, } \\
\text { measurement, } \\
\text { postmeasurement analyses }\end{array}$ & 2 months prior to HFIR startup \\
\hline & $\begin{array}{l}\text { Planning for measurements to } \\
\text { support revision of safety basis } \\
\text { documents }\end{array}$ & November 2006 \\
\hline
\end{tabular}




\section{REACTOR ANALYSES}

At the start of the fiscal year, insufficient data were available to judge whether a diffusion barrier would be needed between the uranium/molybdenum alloy fuel (10 wt \% Mo, termed U-10Mo) and the aluminum clad. Studies performed in FY 2006 indicated that fuel composed of uncoated U-Mo particles dispersed in aluminum could possibly achieve the performance goals that had been established in Ref. 1. Consequently some studies of dispersion fuels were conducted at the start of FY 2007 and were documented in Ref. 5. A summary of those studies is presented here. During the latter part of FY 2007, material irradiations performed in the Advanced Test Reactor led members of the fuel development task to conclude that a diffusion barrier coating would be necessary for the U-Mo fuels. Consequently, the reference LEU fuel for the HFIR is a monolithic foil, and studies of that fuel are also presented in this section. Multidimensional fuel grading studies ${ }^{6}$ indicate that an LEU fuel can meet the performance parameters identified in Ref. 1, doing so requires a modest increase in reactor power. Improvements in analysis methods are under way so that the accuracy and precision of calculated safety margins can be improved from current values and the manufacturing process for LEU fuel (to be developed) can be optimized. Improved accuracy and precision of safety margins will result in minimization of the capital expense associated with an increase in reactor power.

\subsection{DISPERSION FUEL STUDIES}

Several types of dispersion fuel have been analyzed: coated and uncoated (with $\mathrm{Nb}$ ), and U-10Mo and U-7Mo (7 wt \% Mo in U-Mo alloy) material. Studies presented here were based on uncoated U-7Mo dispersion fuel. The U-7Mo dispersion fuel consists of minute fuel particles, of approximately the same diameter as $\mathrm{U}_{3} \mathrm{O}_{8}$ particles in the current $\mathrm{HEU}$ fuel, intermixed with a silicon-stabilized aluminum powder. It was assumed that a diffusion barrier was not required, so the dispersion particles in this current study were assumed to be bare, spherical, U-7Mo particles.

Two of the assumptions in Ref. 1 are modified for these studies. The fuel form is U-7Mo, and the packing fraction is assumed to be 0.55 (instead of 0.5), as presented in Table 1.1. U-7Mo is chosen because its density is slightly greater than $\mathrm{U}-10 \mathrm{Mo}$, but irradiation performance is comparable. The higher density and higher volume fraction result in higher fuel loading per unit thickness and lead to longer cycle length, and full-power level of the HFIR. Table 2.1 lists the specific assumptions and characteristics of the U-7Mo dispersion fuel as represented in the models for the scientific code packages.

Table 2.1. Assumptions for the dispersion calculations

\begin{tabular}{ll}
\hline Dispersion fuel material & $\mathrm{U}-7 \mathrm{wt} \%$ Mo dispersed in aluminum \\
Fuel uranium density & $8.7 \mathrm{gU} / \mathrm{cm}^{3}$ \\
U-Mo volume fraction & $55 \%$ \\
Aluminum volume fraction & $45 \%$ \\
HFIR power level (core lifetime burnup) & $85 \mathrm{MW}(26 \mathrm{FPd})$ \\
\hline
\end{tabular}

\subsubsection{Design and Performance Parameters for a U-7Mo Fuel}

The monolithic studies showed that the fuel loading required to achieve equivalent cycle length and burnup as the current HEU cycle is about $17 \mathrm{~kg}$ of ${ }^{235} \mathrm{U}$. This parameter is generally independent of fuel form-monolithic or dispersion. However, the reduced uranium density in the dispersion fuels leads to the thickness of the fuel meat being much greater for dispersion fuels than for monolithic fuels. 
The power-level and core lifetime performance of LEU fuels in HFIR depends on the density of

${ }^{235} \mathrm{U}$, the amount of ${ }^{238} \mathrm{U}$, and the relative amount of molybdenum. In addition, the ultimate distribution of the fuel material in the fuel plates (and between the inner and outer fuel elements) has a major effect on the HFIR performance. Combinations of operating power and cycle length, determined in FY 2006, are shown in Table 2.2.

Table 2.2. Operating conditions for FY 2006 U-10Mo dispersion fuel simulations

\begin{tabular}{lccr}
\hline \multicolumn{1}{c}{ Case } & $\begin{array}{c}\text { Operating } \\
\text { power } \\
\text { (MW) }\end{array}$ & $\begin{array}{c}\text { 235 U loading } \\
\text { (kg) }\end{array}$ & $\begin{array}{c}\text { Cycle length } \\
\text { (MWd) }\end{array}$ \\
\hline Current, HEU & 85 & 9.4 & 2210 \\
Coated LEU, maximum operating power & 88 & 10.9 & 935 \\
Coated LEU, maximum cycle length & 40 & 17.1 & 2805 \\
Uncoated LEU, maximum operating power & 85 & 13.2 & 1870 \\
Uncoated LEU, maximum cycle length & 77 & 17.5 & 2465 \\
\hline
\end{tabular}

In the U-7Mo dispersion fuel cases, the shape of the ${ }^{235} \mathrm{U}$ distribution was assumed to be the same as the unconstrained minimum-thickness monolithic fuel case (from FY 2006 studies) with the peak thickness expanded to $688 \mu \mathrm{m}$ ( 27.1 mils), the same maximum fuel thickness as the current HEU fueled core. This methodology allowed for maximum ${ }^{235} \mathrm{U}$ loading under the constraint of the previously identified optimum fuel grading distribution. This methodology is not guaranteed to yield the maximum operating power (radial peaks could be reduced by shifting fuel toward the center of the plate) but likely yields an operating power close to the maximum due to axial end peaking likely being the principal factor in establishing maximum operating power.

The current HFIR HEU core has $27.5 \%$ of its ${ }^{235} \mathrm{U}$ in the inner fuel element (IFE). However $37.3 \%$ of the HFIR power in the IFE and $62.7 \%$ in the outer fuel element (OFE). Using U-7Mo uncoated dispersion fuel in HFIR increases the ${ }^{235} \mathrm{U}$ content of the fuel plates, as compared to the graded U-10Mo dispersion fuel cases, because of the higher uranium density of the U-7Mo fuel. The net fuel grading with the U-7Mo dispersion fuel was sufficient to allow for an operational power level of $85 \mathrm{MW}$, while satisfying the power density and coolant enthalpy constraints, and the cycle length for this uncoated dispersion fuel case meets the target reference 26-d (at full power) cycle (2210 MWd).

To the extent possible, increasing the ${ }^{235} \mathrm{U}$ fractional loading in the IFE has the desirable effect of increasing the HFIR core cycle length, though the trend tends to level off in the core loading range of 15 to $18 \mathrm{~kg}{ }^{235} \mathrm{U}$ as the result of the depression of the thermal neutron flux peak occurs in the core with high fuel loadings. The fuel meat thickness profiles for the uncoated U-7Mo dispersion fuel cases are shown in Table 2.3.

Computational simulations of reactor performance were performed with the HFIR critical for $26 \mathrm{~d}$ at the 85-MW full-power level; the control absorbers were adjusted in the simulation to be within $\sim 0.2 \%$ reactivity of critical. MCNP5 ${ }^{7}$ models of the HFIR core were used to analyze the HEU and LEU cores; the results compared favorably with the beginning of cycle (BOC), diffusion theory, BOLD VENTURE ${ }^{8} \mathrm{k}_{\text {eff }}$ determinations for these same cases. The results of the calculations indicate that the required ${ }^{235} \mathrm{U}$ fuel loading increases from $9.4 \mathrm{~kg}$ for HEU to about $16 \mathrm{~kg}$ for the LEU case.

Figure 2.1 shows a comparison of the uncontrolled $\mathrm{k}_{\text {eff }}$ curve for the HEU case and the dispersion, U-7Mo LEU case. These results show the effect of the fissile plutonium generation in the LEU cycle; that being a reduced slope in the $\mathrm{k}_{\text {eff }}$ curve compared to the HEU core. The excess reactivity at $26 \mathrm{~d}$ is similar for the HEU and LEU cases, but not the same. Consequently, the estimate for the ${ }^{235} \mathrm{U}$ loading of $16 \mathrm{~kg}$ is likely slightly low. If further studies were to be conducted, beginning-of-life (BOL) inventory should be increased to match the end-of-cycle (EOC) reactivity of the HEU core. The 
Table 2.3. Uncoated LEU U-7Mo dispersion fuel profile and the current HEU fuel profile

\begin{tabular}{|c|c|c|c|c|c|}
\hline \multirow{2}{*}{$\begin{array}{l}\text { Distance } \\
\text { along } \\
\text { inner } \\
\text { element } \\
\text { plate } \\
\text { (cm) }\end{array}$} & \multicolumn{2}{|c|}{$\begin{array}{l}\text { Thickness of fuel meat } \\
\text { (mils) }\end{array}$} & \multirow{2}{*}{$\begin{array}{c}\text { Distance } \\
\text { along } \\
\text { outer } \\
\text { element } \\
\text { plate } \\
(\mathrm{cm}) \\
\end{array}$} & \multicolumn{2}{|c|}{$\begin{array}{l}\text { Thickness of fuel meat } \\
\text { (mils) }\end{array}$} \\
\hline & $\begin{array}{c}\text { LEU U-7Mo } \\
\text { (in aluminum) } \\
\text { dispersion fuel }\end{array}$ & $\begin{array}{l}\mathrm{HEU} \\
\mathrm{U}_{3} \mathrm{O}_{8}\end{array}$ & & $\begin{array}{c}\text { LEU U-7Mo } \\
\text { (in aluminum) } \\
\text { dispersion fuel }\end{array}$ & $\begin{array}{l}\mathrm{HEU} \\
\mathrm{U}_{3} \mathrm{O}_{8}\end{array}$ \\
\hline 0.252 & 5.0 & 10.2 & 0.191 & 9.1 & 15.3 \\
\hline 0.448 & 5.6 & 11.6 & 0.216 & 10.1 & 15.6 \\
\hline 1.203 & 5.9 & 15.5 & 0.395 & 15.6 & 16.9 \\
\hline 2.439 & 9.8 & 20.5 & 1.134 & 22.6 & 23.0 \\
\hline 3.811 & 12.7 & 24.4 & 2.256 & 27.1 & 27.1 \\
\hline 5.314 & 13.3 & 24.6 & 3.449 & 26.0 & 25.5 \\
\hline 6.969 & 11.1 & 21.5 & 4.655 & 19.1 & 20.7 \\
\hline 7.985 & 8.3 & 18.6 & 5.908 & 12.1 & 14.7 \\
\hline 8.091 & 8.2 & 18.3 & 6.731 & 10.1 & 11.5 \\
\hline
\end{tabular}

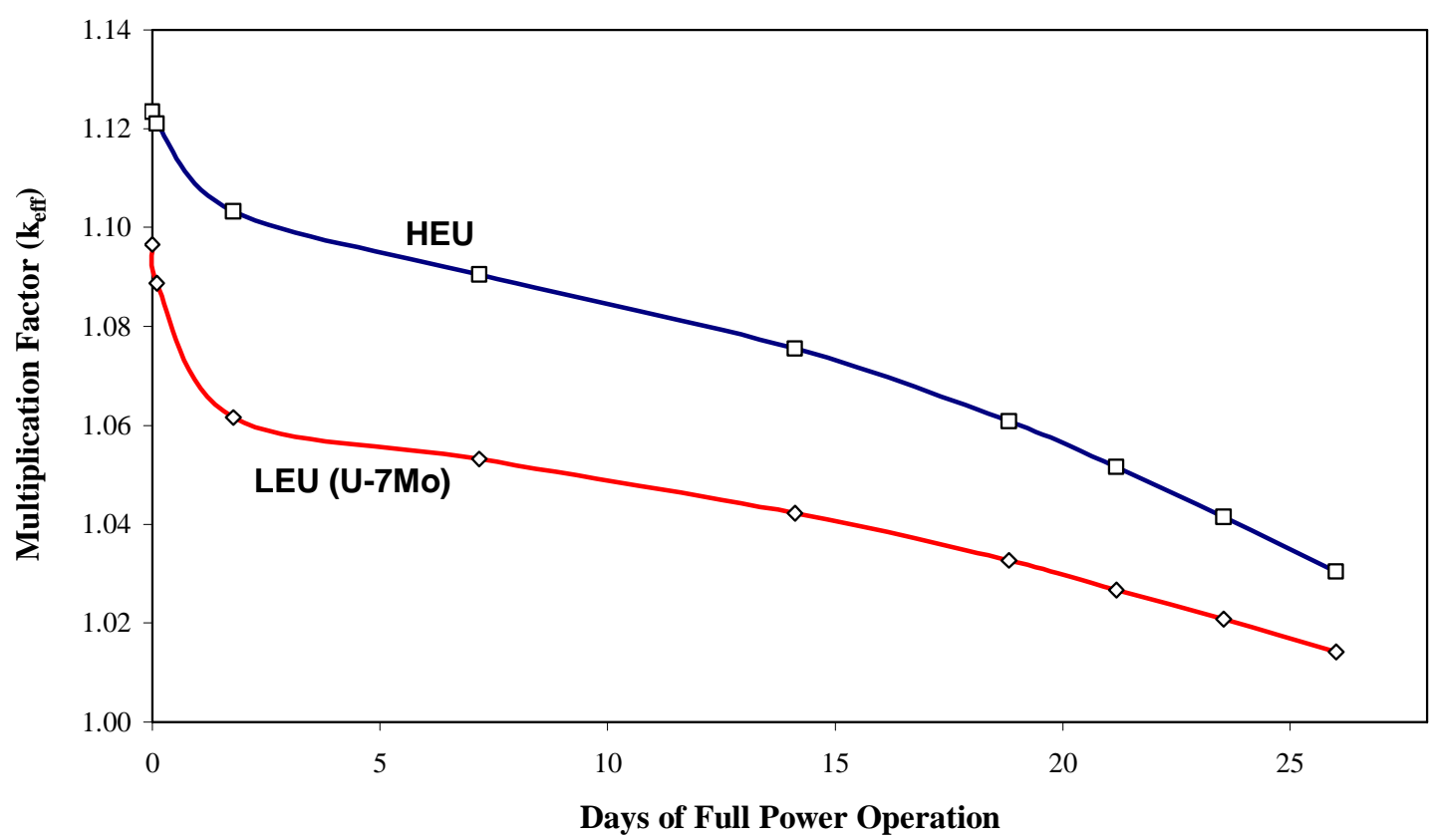

Fig. 2.1. Comparison of $k_{\text {eff }}$ for U-7Mo dispersion LEU and current HEU HFIR cores.

reduced molybdenum content of the U-7Mo fuel relative to the U-10Mo fuel does reduce parasitic neutron absorption and results in a BOL core inventory of uranium for the U-7Mo fuel that is slightly less than that of the U-10Mo fuel.

The primary performance parameters evaluated include the thermal neutron flux in the central flux trap and the outer beryllium reflector, as presented in Table 2.4. A comparison of the flux values shows that there is a reduction of the thermal neutron fluxes at the EOC conditions by $\sim 12 \%$ in the outer beryllium reflector. 
Table 2.4. Thermal neutron flux results of the U-7Mo dispersion fuel core compared to the FY 2006 U-10Mo monolithic fuel core and the current HEU core

\begin{tabular}{lccc}
\hline \multicolumn{1}{c}{ Parameter } & HEU & $\begin{array}{c}\text { LEU } \\
\text { (monolithic U-10Mo) }\end{array}$ & $\begin{array}{c}\text { LEU } \\
\text { (dispersion U-7Mo) }\end{array}$ \\
\hline $\begin{array}{l}\text { Peak thermal neutron flux in } \\
\text { reflector (neutrons/cm }{ }^{2} \mathrm{~s} \text { ) }\end{array}$ & & & \\
$\quad$ BOC & $1.1 \times 10^{15}$ & $1.1 \times 10^{15}$ & $1.1 \times 10^{15}$ \\
$\quad$ EOC & $1.7 \times 10^{15}$ & $1.5 \times 10^{15}$ & $1.5 \times 10^{15}$ \\
$\begin{array}{l}\text { Peak thermal neutron flux in } \\
\text { central target (neutrons/cm }{ }^{2} \mathrm{~s} \text { ) }\end{array}$ & & & \\
$\quad$ BOC & $2.6 \times 10^{15}$ & $2.5 \times 10^{15}$ & $2.6 \times 10^{15}$ \\
EOC & $2.7 \times 10^{15}$ & $2.5 \times 10^{15}$ & $2.5 \times 10^{15}$ \\
\hline
\end{tabular}

The fast and thermal radial neutron flux distributions at BOC and EOC (at midplane) are shown in Fig. 2.2 for the U-7Mo HFIR core. The thermal neutron flux is defined as up to $0.625 \mathrm{eV}$, and the fast flux shown in the figure is defined for neutrons with energy greater than $0.1 \mathrm{MeV}$.

As part of the U-7Mo HFIR core modeling simulation, the control element positions during the fuel cycle case were updated and improved. Figure 2.3 shows the progression of the positions of the control elements in HFIR during the simulated U-7Mo dispersion fuel core case, compared to the current HFIR HEU core behavior. (The HEU control element at 21 effective full power days [EFPD] was found to have been inaccurately set at the position corresponding to 24 EFPD.)

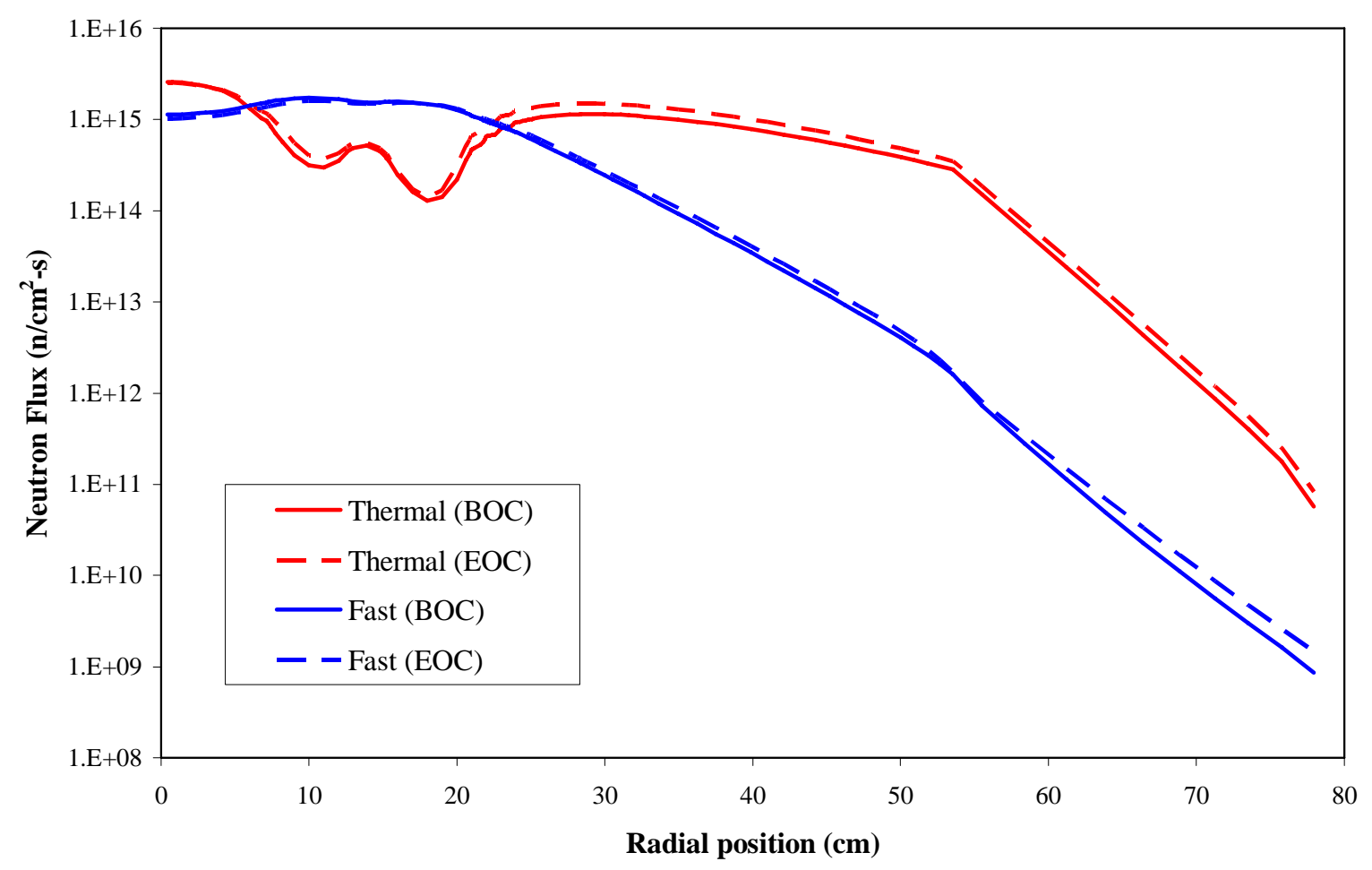

Fig. 2.2. Radial fast $(>0.1-\mathrm{MeV})$ and thermal $(<0.625-\mathrm{eV})$ neutron flux distributions in HFIR. 


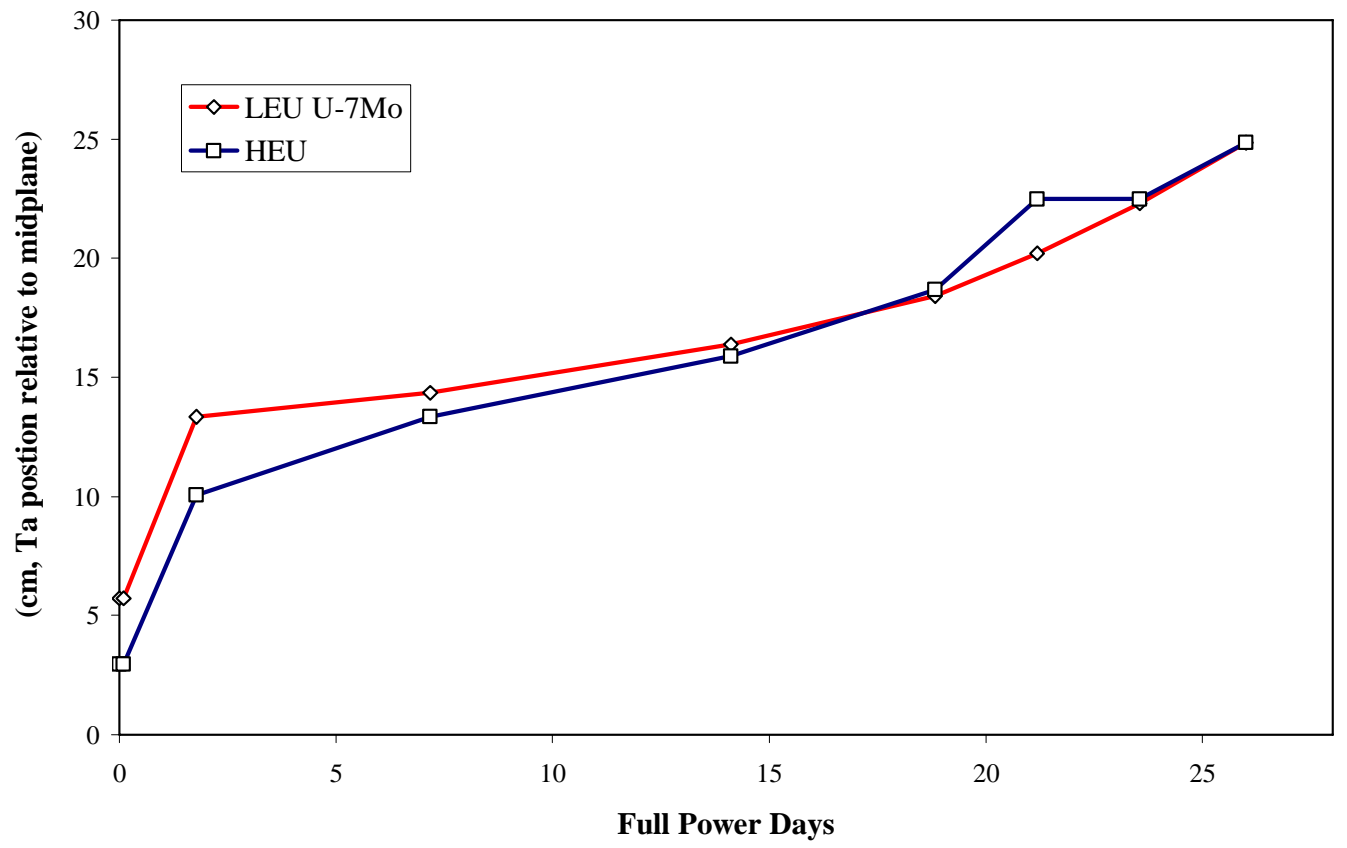

Fig. 2.3. Control element positions for the HEU and LEU simulations.

The HEU core requires the control elements to be inserted more at BOC than in the U-7Mo (LEU) dispersion fuel core, because of the higher reactivity of the HEU core. The U-7Mo dispersion core simulation has the absorbers withdrawn in a series of steps (as seen in Fig. 2.3) to keep the core reactivity as constant as possible during the simulation. Figure 2.4 shows a plot of $\mathrm{k}_{\text {eff }}$ vs time for the LEU U-7Mo HFIR dispersion fuel core, which is seen to be very close to the criticality during the simulation. Reactivity deviations from $\mathrm{k}_{\mathrm{eff}}=1$ are less than $\pm 0.5 \% \Delta \mathrm{k} / \mathrm{k}$. The target EOC core reactivity is currently $\mathrm{k}_{\mathrm{eff}}=1.02$ with the control absorbers fully withdrawn.

BOLD VENTURE and MCNP calculations were performed in FY 2007 for a range of ${ }^{235} \mathrm{U}$ content with the U-7Mo dispersion fuel, from as low as $15.1 \mathrm{~kg}$ to $17.5 \mathrm{~kg}$ (equivalent to the ${ }^{235} \mathrm{U}$ loading of the FY 2006 monolithic U-10Mo case). It was seen that as the concentration of ${ }^{235} \mathrm{U}$ is increased, the corresponding increase in ${ }^{238} \mathrm{U}$ concentration offsets to a large extent the net reactivity increase in the core. The natural molybdenum has a small but measurable diminishing effect on the core reactivity as the molybdenum concentration increases.

The MCNP result for the BOC U-7Mo dispersion fuel case, at $\mathrm{T}=300 \mathrm{~K}$, is $\mathrm{k}_{\mathrm{eff}}=0.9939 \pm 0.0005$. The reactivity effect of the natural molybdenum content in the U-7Mo core is $\Delta \mathrm{k}=0.57 \pm 0.06 \%$ (5.83 $\mathrm{kg}$ of total molybdenum). Note that the U-7Mo core has $5.83 \mathrm{~kg}$ of molybdenum at BOC, as compared to $9.87 \mathrm{~kg}$ of molybdenum at BOC in the earlier monolithic U-10Mo case from FY 2006.

The studies of bare, U-7Mo dispersion fuel are now considered to be academic in nature. They are illustrative of the degree to which dispersion fuels might be able to approach current, HEU-fueled HFIR performance. Criteria established in Ref. 1 coupled with the irradiation performance of uncoated (no diffusion barrier) U-10Mo fuel during FY 2007 leads to the conclusion that only monolithic foil LEU-Mo fuel can meet HFIR performance criteria. 


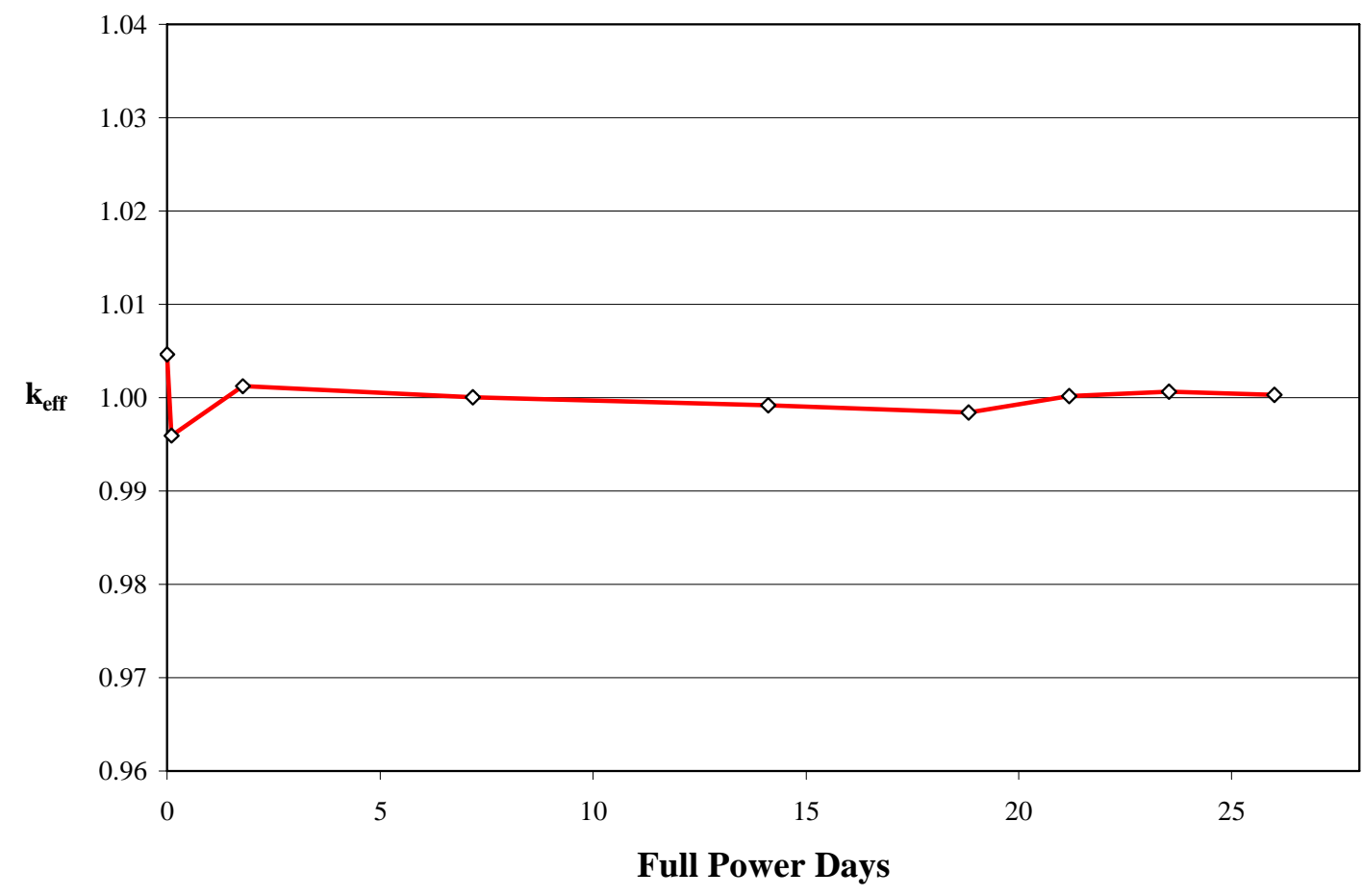

Fig. 2.4. Effective multiplication factor ( $\left.k_{\mathrm{eff}}\right)$ for $\mathrm{LEU}$ case showing that $k_{\mathrm{eff}}$ was maintained within $\pm 0.5 \%$ of unity during operation.

\subsubsection{Comments on Zirconium-based Fuels}

Because fuel irradiation tests during FY 2007 yielded the conclusion that some type of diffusion barrier is required to exist between the U-Mo fuel and the aluminum clad and filler material, it is logical to consider substitute materials for aluminum. Considering the materials that have been used for reactor applications and under the constraint of minimizing parasitic neutron absorption in the reactor core (aluminum absorption cross section is quite low), the only choice would be zirconium or an alloy of zirconium. Known difficulties with substituting zirconium for aluminum are cost and weight. Zircaloy ${ }^{\mathrm{TM}}$, a zirconium alloy currently used in power reactor fuels has a density of $6.44 \mathrm{~g} / \mathrm{cm}^{3}$ vs the Al-6061 density of $2.70 \mathrm{~g} / \mathrm{cm}^{3}$. Because a HFIR core (inner and outer element) is mostly aluminum, the weight of a core would increase by a factor of 2.4 if Zircaloy were substituted for aluminum. This increase in weight, accompanied by the increase in uranium weight of an LEU core, relative to an HEU core (a factor of 8.2 due to reduction in enrichment and increase in critical mass of ${ }^{235} \mathrm{U}$ ) would require that a new structural analysis be performed of the core support grid with the potential for required strengthening of the reactor support structure. From Ref. 9, zirconium of about $99.6 \%$ purity is available at a cost of about $\$ 150 / \mathrm{kg}$; a recent purchase of aluminum for HFIR HEU fuel fabrication was made at a cost of $\$ 15 / \mathrm{kg}$. Pressing a flat Zircaloy plate to a HFIR involute shape has not been performed. The ductility of Zircaloy is less than that of aluminum, but whether this property would significantly impact the plate production process is not known. It is possible that zircaloy clad fuel plates could be made thinner than the current aluminum fuel plates. Thinner plates would result in more plates per unit volume in the core with consequent reduced surface heat flux under constant power. The thermal conductivity of Zircaloy is lower than that of aluminum, but the low operating temperature of the HFIR coupled with the small thickness of HFIR plates and the higher melting point of zirconium relative to aluminum would minimize the impact of the difference. 


\subsection{TWO-DIMENSIONAL GRADED MONOLITHIC FUEL}

Studies conducted during prior fiscal years have been limited to changes in the region-betweenthe-clad (fuel meat region) of the HFIR plates. No changes have been assumed for any of the reactor operating conditions (inlet, outlet temperatures, and system pressure) or for the geometry of the reactor core (diameter, materials, and fuel plate dimensions). A conclusion of these studies was that the current level of reactor performance as defined by parameters listed in Ref. 1 could not be maintained with LEU fuel with the reactor operating at $85 \mathrm{MW}$. From those studies, the hypothesis was developed that if the reactor power could be increased to the original design level of $100 \mathrm{MW}$ - the HFIR was operated at $100 \mathrm{MW}$ for more than 20 years - the performance parameters could be maintained at their current levels. One method of obtaining this higher power level consistent with the original assumption of only considering changes to the fuel meat region was to smooth the power distribution by grading (or tapering) the fuel thickness in both the axial and radial directions (currently the fuel is graded only in the radial direction).

From radial-grading studies conducted during FY 2006, new LEU fuel thickness profiles were developed. Fuel profiles for the inner and outer elements for monolithic (U-10Mo, FY 2006 studies) and dispersion (U-7Mo, reported here previously) fuels are shown in Fig. 2.5 (inner element) and Fig. 2.6 (outer element).
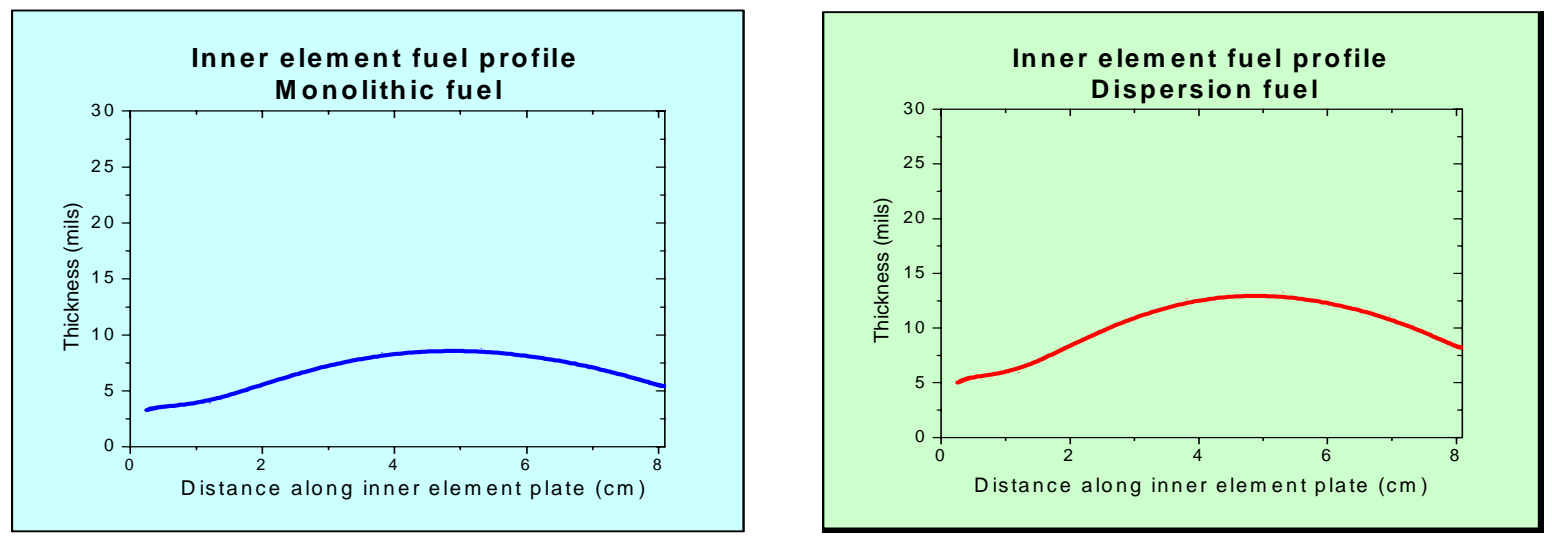

Fig. 2.5. Inner element LEU fuel profiles.
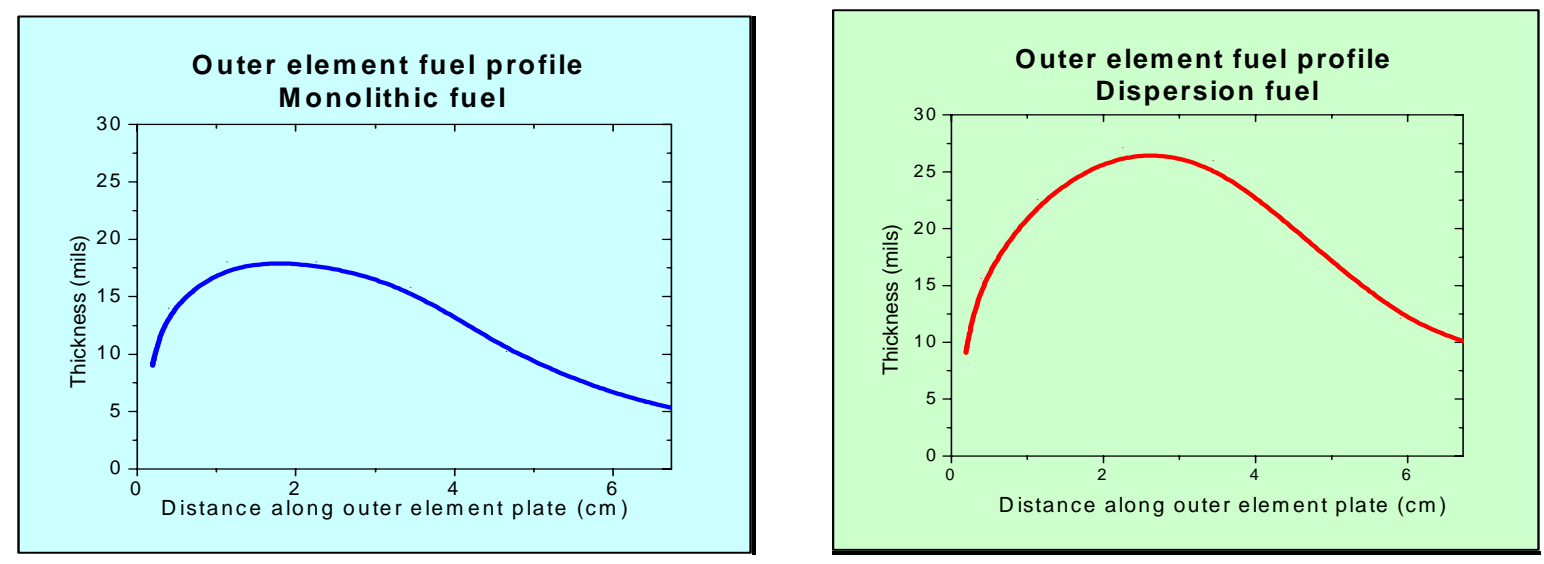

Fig. 2.6. Outer element LEU fuel profiles. 
Monolithic fuels could be constrained by minimum foil thickness that can be economically fabricated. Dispersion fuel is constrained by the available meat thickness in the current HFIR fuel plate. Figure 2.7 shows the power profile in the HFIR for the "only radially graded" monolithic fuel design. The coolant in HFIR flows downward through the core, and the lower axial edge peak is the limiting location for avoiding incipient boiling.

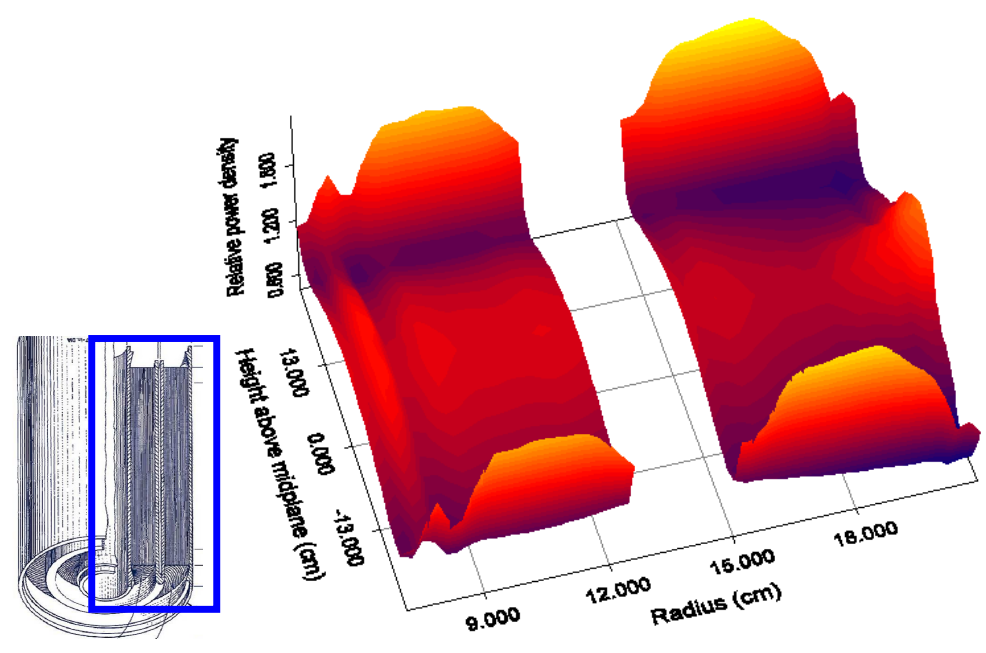

Fig. 2.7. BOL power distribution for "only radial graded" fuel (diffusion theory; profile for blue highlighted region of core).

\subsubsection{Design and Performance Parameters}

Fuel densities at the upper and lower edges of the fuel elements were reduced, and the operating power resulting from the thermal-hydraulic margins identified in Ref. 1 was recalculated for a new power distribution based on Monte-Carlo-normalized diffusion theory. The height of the reduceddensity axial zones was not optimized, but reducing the fuel density by $50 \%$ over the top and bottom $2.5 \mathrm{~cm}$ of the fueled region results in an estimated BOL operating power of $102 \mathrm{MW}$ and an estimated end-of-life operating power of $97 \mathrm{MW}$. End-of-life reflector peak thermal flux equals the current HEU value.

These studies are "proof-of-principle" only. Much design work remains including optimization of the length of the axially graded regions and the profile of the fuel shape in those regions. Furthermore, a recalculation of uranium mass to meet lifetime requirement is needed. The ratio of LEU to HEU fluxes at the location of the HFIR cold source is shown in Appendix A. This study shows that with the existing thermal-hydraulic analysis methodology, attaining equivalent performance with LEU fuel as is currently available with HEU is plausible given a moderate increase in reactor power. While moderator heat load has been accurately predicted for the current HEU fuel cycle, an increase in reactor power to $100 \mathrm{MW}$ might require redesign of the cold source cooling system (modifications to refrigeration units).

\subsubsection{Kinetics and Transient Analyses}

A computational model of the reactor core of the HFIR was developed to analyze nondestructive accidents caused by transients during reactor operation. Such model was built based on the available description parameters Ref. 1 and the latest version of the nuclear analysis software package called Program for the Analysis of Reactor Transients (PARET). ${ }^{10}$ Validation calculations were performed and compared to published results. Analyses were performed with the model for the current HEU fuel 
and compared to calculations performed with other methods and documented in the HFIR safety basis. ${ }^{11}$ Finally, the model was used to analyze the behavior of the reactor under transients with LEU$10 \mathrm{Mo}$ monolithic fuel. The study showed that the presence of fertile isotopes in LEU fuel that increase the neutron resonance absorption reduce the impact of transients on the fuel and enhances the negative reactivity feedback. The current HEU fuel performance under transients bounds the LEU performance for those transients that were studied. These studies are documented in Ref. 12.

\subsection{METHODS DEVELOPMENT}

One goal is common to all methods development tasks_-simplify the design of an LEU fuel plate for HFIR. If possible, elimination of the axial grading in each fuel plate-whatever that optimal grading profile may be-will significantly reduce the cost of fabricating LEU fuel for HFIR given that more than 5000 fuel plates would have to be produced each year. Two methods development tasks are devoted to improving the accuracy and precision of neutronics methods; one task is devoted to improving the accuracy of determining the margin to incipient boiling in an LEU core.

\subsubsection{Multidimensional Cross Section Processing}

Except for the MCNP studies, the neutronics analyses of HFIR performance with LEU fuel that have been performed to date used a set of computational tools that has existed since the early 1990s. This set includes the BOLD-VENTURE code system, a 3-D multigroup diffusion solver with depletion capabilities. The ability to provide fast solutions, perform depletion calculations, and allow changes in the geometry during depletion (i.e., changes in the control plates locations) make this methodology a suitable tool to perform fuel grading scoping studies. Yet comparison to MCNP calculations and to critical experiment measurements shows that this methodology overestimates the local power densities along the edges of the reactor core-axial and radial.

The development of a new cross section processing methodology started in FY 2007, with the aim of ensuring a more appropriate representation of the cross section data for the fuel regions located near the edges of the fuel element. Fuel regions at the edges of the elements are characterized by larger neutron leakage and neutron flux spectra much different than the average flux in the fuel element. Better cross section representation will improve the results of the VENTURE calculation. The new methodology is based on the TRITON/NEWT sequence newly available in SCALE ${ }^{12}$ that allows 2-D depletion calculations for arbitrary-mesh geometries. It is expected that the 2-D cross section processing approach will provide a better representation of the spatial dependence of the neutron flux, especially important for the fuel regions at the top and bottom of the fuel elements. At the same time, the use of the TRITON sequence will make available the cross section data as a function of burnup.

\subsubsection{2-D NEWT model of HFIR}

NEWT is a transport theory solver that is called by the SCALE module TRITON. The 2-D NEWT model of HFIR represents an axial cross section of the reactor core that cuts the cylindrical core into two equal halves. Due to symmetry, only one quarter of the axial cut is modeled, as illustrated in Fig. 2.8. Reflective boundary conditions are imposed on the left and bottom of the bounding surfaces, and white boundary conditions on the other two edges of the configuration. The geometry and material composition data are consistent to that used in the 3-D MCNP detailed model of HFIR developed by Xouby and Primm ${ }^{13}$ and in the VENTURE model of HFIR used for 1-D grading studies. However, no control plates or targets are included in the NEWT model. The fuel radial grading is modeled in detail. The reduced density in the axial zones-described in Sect. 2.2.1 — can also be included explicitly. Therefore, the resulting microscopic cross sections should account for the changes in flux at the edges of the fuel element as compared to the fuel element average flux. 


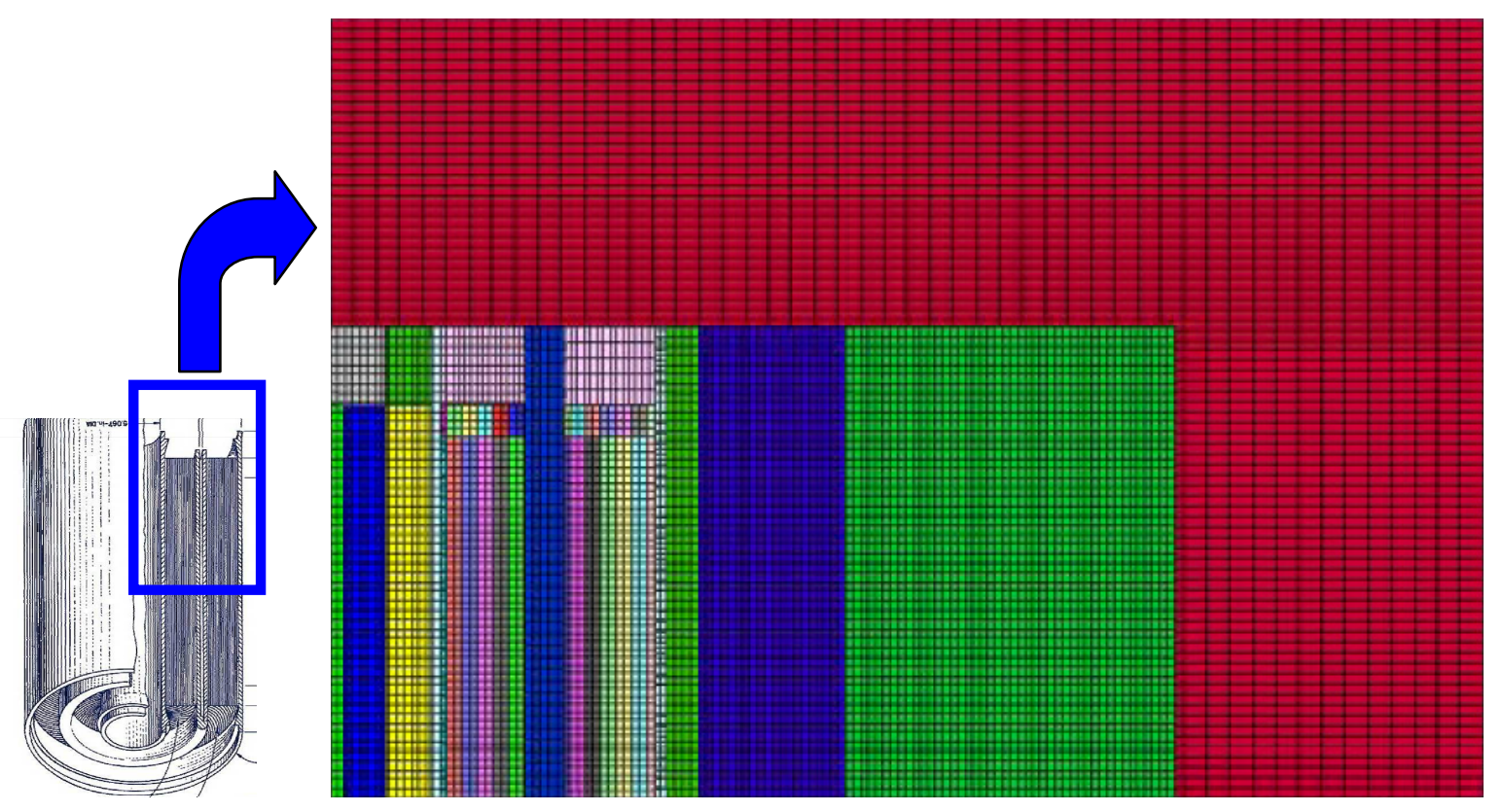

Fig. 2.8. 2-D NEWT model of HFIR for broad group cross section generation.

\subsubsection{Verification of the 2-D NEWT model}

As a first verification step, the spatial variation across fuel elements of relevant four-group macroscopic cross sections (fission, capture) and fluxes obtained with the NEWT model was compared to the corresponding results obtained with a similar simplified 3-D MCNP transport model. This simplified MCNP model, illustrated in Fig. 2.9, was built to be consistent with the NEWT model;

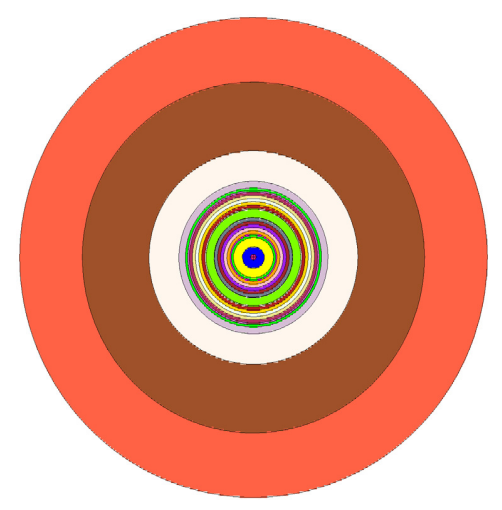

(a) radial view

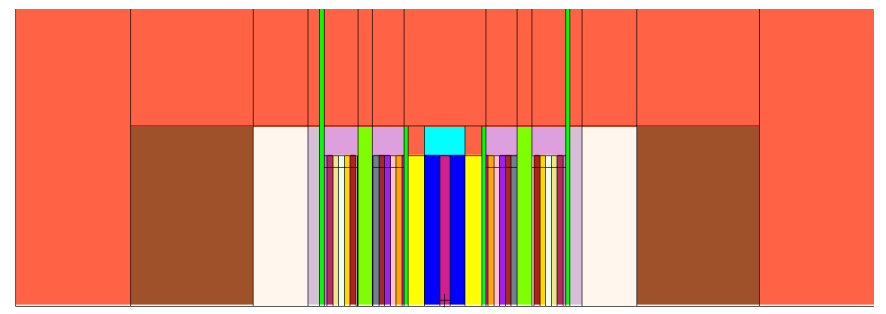

(b) axial view

Fig. 2.9. A 3-D MCNP simplified model of HFIR. 
therefore, it does not include as many details as the detailed MCNP model of HFIR. Continuous energy cross section data were used for MCNP, whereas NEWT calculations employed a 238-group SCALE transport library. Both cross section data were based on ENDF/B-V nuclear data files.

The comparison between the two models was performed for the system multiplication factor $\mathrm{k}_{\mathrm{eff}}$ and for fission and capture macroscopic cross sections for selected regions in the fuel elements. Good agreement was observed for the k-effective values. The maximum difference between the two methods in the case of the macroscopic fission cross section over the thermal energy range for the spatial elements considered was 3\%, as illustrated in Fig. 2.10. The good agreement of the results obtained with the two models confirmed the adequacy of pursuing the new 2-D methodology. It showed that the transport solutions obtained with the two models are consistent.

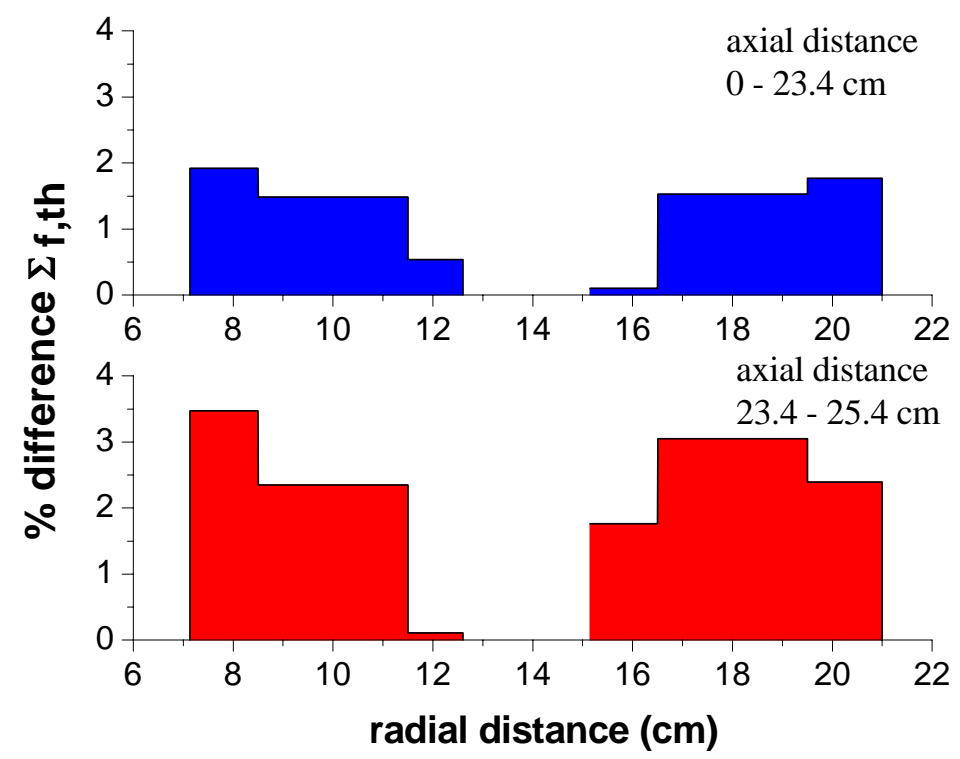

Fig. 2.10. Comparison of macroscopic thermal fission cross section from MCNP and NEWT.

As a result of the verification study, it was found that there were large differences of the microscopic transport cross sections from the NEWT model as compared to corresponding values derived from other deterministic methods. These differences were found to be due to a deficiency in the transport cross section estimate in NEWT. The algorithm to estimate this cross section and its implementation in the code has been revisited and modified to be consistent with the approach existent in other modules of the SCALE code system. Assessment of algorithm performance is on-going.

\subsubsection{Depletion Monte Carlo Methods}

ALEPH is a Monte Carlo-based depletion tool developed at SCK/CEN in Belgium that couples a Monte Carlo transport code from the MCNP family of codes (e.g., MCNP, MCNPX) and the point depletion code ORIGEN 2.2. An earlier version of the code was used in the past to perform depletion calculations for HFIR. This code, developed as a Ph.D. dissertation work, is currently archived at SCK/CEN.

During FY 2007, effort was spent to install and test the code at ORNL. This task proved to be not trivial because the code documentation is poor and there are pitfalls that are not documented at all in the manual. ALEPH was tested by its developer on a LINUX platform for a limited number of $\mathrm{C}++$ compilers (code is written in $\mathrm{C}++$ ) and for coupling of the MCNPX code with a modified version of ORIGEN2.2. At ORNL, ALEPH was successfully installed on a Linux computer on which the 
recommended $\mathrm{C}++$ compiler, version 3.2 or later, was available, and coupled the already available, installed and tested, latest version of MCNP (MCNP5) and the modified ORIGEN2.2.

The installed version is currently under testing. One of the two reference test files received from the code developer, which corresponds to a $\mathrm{UO}_{2}$ pin cell burned up $60 \mathrm{GWd} / \mathrm{MTU}$, was run to completion. A comparison of the output data indicates a difference as compared to the reference data. It may be due to possible differences between MCNP5 and MCNPX. The differences are currently under investigation.

A second test case consisted of a HFIR model, which was run by the code developer on a cluster using a parallel version of MCNPX. At ORNL, the same case, which has 25 burnup steps, was started and run for about 3 weeks to complete 19 out of the 25 burnup steps. Given the computational effort required for simulations of large configurations, a parallel version of the $\operatorname{MCNP}(\mathrm{X})$ code would need to be installed and tested to be used with ALEPH.

\subsubsection{Multidimensional Steady State Heat Transfer}

The steady state thermal-hydraulics analysis methodology for HFIR is unchanged from the original development that occurred at the time of construction of the reactor (mid-1960s ${ }^{14}$ ). Limitations of this methodology include modeling of heat transport in only one dimension, modeling of only a single coolant channel in the inner element and a single coolant channel in the outer element, inability to accommodate turbulent mixing of coolant flow, and lack of statistical treatment of uncertainties. Accounting for some or all of these inadequacies would show that the safety margin (margin to incipient boiling) for an LEU fuel that is graded in only one direction (radial) is adequate.

Research Reactors Division (RRD), ORNL, has adopted the finite-element, multiphysics, numerical analysis program, COMSOL, for modeling thermal and fluid flow behavior. Consistent with RRD's current practice, development of the thermal-hydraulic model for LEU fuel will be based on the COMSOL software package. COMSOL is well suited to multiphysics evaluations but is also demanding of computational power and memory during execution.

Modern computational fluid dynamic (CFD) simulation, in conjunction with conduction modeling in the fuel and cladding, allows matching of the spatial power distribution in the fuel volume. It also allows detailed simulation of the impact of fuel manufacturing flaws, fuel cooling channel dimensional variations, and fuel loading uncertainties such that best estimate evaluations of these parameters can be available. During FY 2007, work started to create geometric and material models for the fuel structure and the coolant in a computational format allowing coupled solution of the governing thermal-fluid multiphysics equations. 


\section{FUELS DEVELOPMENT}

In the current, $\mathrm{HEU}$ fuel cycle, funding for $\mathrm{U}_{3} \mathrm{O}_{8}$ production, fabrication of fuel elements, and transportation of both fresh and spent fuel are provided by the reactor operator. Consequently, any expected changes in the cost of these fuel cycle elements must be identified so that sponsors of work performed at HFIR can plan future budgets. While the Reduced Enrichment for Research and Test Reactors (RERTR) Program has committed to supply the first LEU core to HFIR-thereby implicitly agreeing to fund the capital cost of creating a new fuel cycle - the annual operating expense of the fuel cycle will remain a responsibility of the reactor operator. The potential operating cost of an LEU manufacturing process was studied during FY 2007 and documented in Ref. 16. Consistent with the commitment to supply the first LEU core to HFIR is a second area of responsibility for the RERTR program; that being the certification of LEU fuel for use in HFIR. While the RERTR program has developed a set of experiments to achieve "generic qualification," " the fuel qualification plan stipulates that "reactor-specific" qualification tests will follow the generic qualification. ORNL staff have begun the identification of "HFIR-specific" qualification tests that should follow the completion of the generic qualification program. One of those qualification tests was initiated in FY 2007.

\subsection{CONCEPTUAL FUEL MANUFACTURING PROCESS}

The conceptual LEU fuel manufacturing process, also known as a reference flow sheet, presented in Refs. 16 and 18 is based on processes currently being developed by the national program for the LEU foil fuel when available, processes used historically in the manufacture of other nuclear fuels and materials, and processes used in other manufacturing industries producing a product configuration similar to the form required in manufacturing a foil fuel. The processes in the reference flow sheet are within the bounds of known technology and are adaptable to the high-volume production required to process $\sim 2.5$ to 4 tons of U-Mo and produce $\sim 16,000$ flat plates for U.S. reactors annually $(\sim 10,000$ of which are needed for HFIR operations). The reference flow sheet is not intended to necessarily represent the best or the most economical way to manufacture a LEU foil fuel for HFIR but simply represents a "snapshot" in time of technology and is intended to identify the process steps that will likely be required to manufacture a foil fuel. Changes in some of the process steps selected for the reference flow sheet are inevitable; however, no one step or series of steps dominates the overall flow sheet requirements.

A result of conceptualizing a reference flow sheet was the identification of the greater number of steps required for a foil process when compared to the dispersion, HEU fuel process. Additionally, in most of the foil processing steps, bare uranium must be handled, increasing the complexity of these processing areas relative to current operations. Based on estimates of the process step costs, it is apparent that line item funding will be necessary for the construction of an LEU fuel fabrication facility and could take as much as 8 to 10 years to complete. Annual cost to the reactor operator could be two to four times the current cost for HEU fuel.

\subsection{DEVELOPMENT OF A HFIR-SPECIFIC FUEL QUALIFICATION PLAN}

While U-10Mo has been chosen as a reference LEU fuel, a variety of industrial processes exist for creating a fuel foil for HFIR. Various processes were reviewed, and candidates for reference production processes were selected. Once selected, a process to identify HFIR-specific fuel qualification tests was initiated. The first of these tests-forming a radially graded fuel foil-was instigated this year. 


\subsubsection{Review of Possible U-Mo Foil Production and Cladding Processes}

Initial work performed during FY 2007 was centered on identifying and evaluating the feasibility of methods to produce LEU-Mo foils that were graded in two dimensions (across the width and along the length). Four candidate methods for 2-D graded foil fabrication were evaluated.

1. Create the fuel region in the fuel plate using stacked foils of the U-Mo alloy composition eventually selected as the LEU fuel (presently assumed to be U-10 wt \% Mo). These foils would have to be of small thicknesses, approximately 25 to $65 \mu \mathrm{m}$ (0.001 to 0.0025 in.) thick with, at this point, unknown thickness tolerance. Each foil would have constant isotopic composition. If necessary the isotopic composition could vary from one foil to another. The foils would be "stacked" in the fuel plate to produce the necessary 2-D grading in ${ }^{235} \mathrm{U}$ content. A major performance question will be assuring heat transfer between foils and the foil stack to the aluminum clad, that is, bonding of the foil stack to assure good thermal conductivity. One possible approach to fabrication would be fusing the stacked foils using one of two very high intensity infrared (IR) lamps. The heated foils would produce the monolith that would then be trimmed, placed in the aluminum clad, and the edges welded, possibly with friction stir welding (FS). The final bond between fuel and clad would be achieved by rolling, FS, or hot isostatic press (HIP).

2. A second approach would be to produce the fuel meat from U-Mo powder. It would be possible to use two or three powders of varying isotopic composition to create two or three different "wafers." The wafers would be the width of the HFIR fuel meat region but would be considerably shorter than the 20-in. fueled length of the HFIR plate. Radial grading is achieved by depositing powder in a "mold" to make a preform of the fuel section. This preform could then be fused using IR lamp technology. Axial grading would be achieved by stacking the wafers of either different thicknesses or different enrichments (or both) in an aluminum frame. This frame would then be placed into aluminum clad sections, welded, possibly with FS to achieve total closure as well as bonding of the aluminum clad and the fuel, or welded with conventional techniques using HIP to achieve aluminum-fuel bonding, or roll bond.

3. Still a third approach would be to use a deposition process such as magnetron sputtering, electron cyclotron resonance (ECR) plasma-driven sputtering, or plasma spraying to form the fuel meat. Conceptually any of these processes could be used to achieve a fuel section with either a 2-D isotopic tailoring (varying the uranium enrichment) or a graded thickness. It may be possible to deposit the fuel directly onto one-half of the aluminum fuel and then deposit the "cover plate" also using plasma spray, ECR, or a magnetron sputter deposition process. If this could be done, bonding with the plate would be assured. The second (top) plate might also be bonded to the fuelcontaining bottom plate using FS, roll bond, or HIP. The high-intensity IR lamps may be very effective in creating 2-D isotopically graded (varying the uranium enrichment) targets for magnetron or ECR sputtering, fusing to eliminate voids that are usually present in sprayed coating, etc.

4. The fourth approach would be to create a contoured shape on a rolled metal foil by machining or grinding the surface of the foil.

Each of these fabrication scenarios was evaluated, and it was concluded that the fourth method was most feasible. The stacked foil method was determined infeasible mainly due to concerns about the ability to fabricate and handle 0.001 -in.-thick U-Mo foils. Additionally, the precision and repeatability with which the foils could be stacked to produce the needed 2-D grading was thought to be unacceptable. Also, making $\sim 15,000$ plates a year by stacking and fusing ten or more thin foils per plate was thought to be impractical. 
The concept of producing "wafers" from LEU-Mo powder was thought to be too complicated from an operational standpoint. First, maintaining control of powders (and wafers) with varied enrichment was not considered viable. The issues of handling large quantities $(2.2 \mathrm{Mg} /$ year) of reactive metal powders, while not impossible, were thought to be impractical compared to handling foils. And similar to the stacking foils concept, there were concerns about stacking multiple wafers in each plate in the production of 15,000 plates a year.

The third proposed approach initially held the most promise. Being able to deposit the LEU-Mo fuel "meat" onto one of the clad halves and produce the grading by controlling the thickness of the deposit was attractive. This scenario could potentially guarantee the fuel/clad bond, while at the same time provide a reliable way of achieving the fuel grading. Unfortunately, it was believed that the only way to produce the necessary high-temperature gamma-phase U-Mo using a deposition technique was by either depositing the U-Mo on a substrate that was held at temperature where the gamma phase was stable $\left(\sim 580^{\circ} \mathrm{C}\right)$, or to do a postdeposition heat treatment to produce the gamma phase. Either method of producing gamma phase U-Mo is unfeasible if the substrate is the aluminum cladding (melting point $\sim 600^{\circ} \mathrm{C}$ ). The inability to deposit the fuel directly onto the cladding coupled with concerns about the ability to produce fuel foils by a deposition technique on the production scale lead to the conclusion that more traditional foil fabrication techniques were a better choice.

As a result of these studies, option 4 was selected. Selection of the grading process enabled development of a set of qualification tests needed to certify the fuel. The next sections discuss these tests.

Some additional fuel development concepts were considered in addition to U-Mo foil production. One of the key issues in the fabrication of monolithic fuel is achieving a good bond between U-Mo fuel foil, the aluminum cladding, and any potential interface layers. While investigating the production of graded fuel foils by sputtering, a sputter cleaning technique was identified that could potentially allow clad bonding at both low temperature and pressure. It had been shown experimentally on a laboratory scale that pure aluminum bonding at low pressure near room temperature could be accomplished using sputtering to remove the oxide layer from the mating surfaces of the aluminum. ${ }^{19-21}$ While the traditional mechanical and chemical aluminum cleaning methods are performing adequately for the FB and the HIP clad bonding process, it would be a small and worthwhile effort to investigate this sputter cleaning technique.

Using a deposition technique to deposit the cladding was also considered. Clad deposition would afford similar clad bonding as fuel deposition onto the clad, but there were concerns that postdeposition annealing (to achieve the desired aluminum microstructure), if needed, could lead to unwanted U-Al interaction. Also, the feasibility of clad deposition on the production scale was questioned. These issues coupled with the success of the FB and HIP processes tabled this concept. Applying fuel/clad interfacial layers via physical vapor deposition is quite feasible.

\subsubsection{Preliminary Identification of HFIR-specific Fuel Qualification Tasks}

After reviewing generic qualification tests as documented in Ref. 17 and having reached preliminary conclusions on fuel plate geometry (Sect. 2.2) and fuel plate grading process (previous

section) and reviewing the HFIR safety basis, ${ }^{11}$ fuel qualification issues were identified by ORNL staff. Fuel qualification entails performing a set of tests on both integral and separate effects that cover the conditions for Department of Energy (DOE) approval of the safety basis for operation of the reactor or for Nuclear Regulatory Commission (NRC) licensing. As a result of these tests, it should be demonstrated that no fuel failure is expected to occur during normal operation including anticipated operational events; that predictable and limited degradation, which might occur during design basis accidents, will not lead to an uncontrolled release of radioactive materials to the environment; and, preferably, that predictable failure mechanisms, which might occur during severe accidents beyond the design basis, are such that source term releases can be quantified for emergency planning. Achieving 
this goal requires well-defined tests of materials reaction kinetics via "out-of-pile," heated, water immersion tests including corrosion tests of fuel meat and clad in water under prototypic conditions and both fueled and nonfueled irradiation tests at different temperatures and therefore various heating rates and neutron-fluence levels. Table 3.1 is a summary of tests believed to be needed to qualify an LEU fuel for use in the HFIR. The table was distributed to all members of the U.S. High Performance Reactor Conversion Group, and comments were solicited. The table will serve as a basis for the development of a HFIR-specific fuel qualification plan.

\subsubsection{Graded Monolitic Foil-Preliminary Grinding Results}

Initial experiments in surrogate foil contouring by grinding (corresponding to the first row in Table 3.1) were begun during FY 2007. This initial work on the surrogate foil grinding was focused on determining the tolerances and surface finishes that can be attained on flat ground surrogate foil specimens. Grinding tests were performed in the machining research laboratory in the High Temperature Materials Laboratory (HTML) using the Chevalier computer numerical control (CNC) surface grinder, shown in Fig. 3.1. The Chevalier CNC surface grinder is used by the machining research group for a wide range of applications. Many different material combinations/part types have been made. One example was the silicon carbide high-temperature tensile test grip, shown in Fig. 3.2, which required high accuracy and ability to machine hard ceramic materials. The Chevalier was also used to produce test specimens such as the cordierite fracture toughness specimen presented in Fig. 3.3. These specimens required very close thickness tolerances ( 0.0150 in. \pm 0.0002 in.) and smooth surface finishes (similar to LEU fuel foils). Metal test specimens were also machined on the Chevalier. The Ti-6-4 fretting specimen shown in Fig. 3.4 was sliced to the length/width required and then ground to ensure the top and bottom faces were parallel.

For this fuel foil grinding study, steel shim stock is being used as a surrogate for the U-Mo fuel foils. The steel shim stock was procured from McMaster Carr and comes in sheet form 0.020 in. thick. It was chosen primarily for ease of fixturing via the magnetic chuck that is already in place on the grinder. (However, a vacuum chuck is being designed for trials later in the study.) The steel foil stock was cut into grinding specimens that were $5 \mathrm{~cm}$ by $20 \mathrm{~cm}(2 \mathrm{in.} \times 8$ in. $)$ and $5 \mathrm{~cm}$ by $15 \mathrm{~cm}(2 \mathrm{in} . \times$ 6 in.) by electro-discharge machining (EDM). These dimensions were an arbitrary choice made primarily for convenience and to loosely represent the length-to-width ratio of the actual U-Mo fuel foil. The as-received thickness of the steel shim stock was measured using a Mitutoyo digital micrometer. Approximately six to ten measurements across the foil specimen revealed a variation in as-received thickness of $30.5 \mu \mathrm{m}$ (0.0012 in.).

Initial grinding experiments have been done on surrogate foil specimens, similar to that shown in Fig. 3.5. For the first grinding experiment, a 2 in. $\times 6$ in. AlNiCo bar magnet was used to hold a 2 in. $\times$ 6 in. specimen, but unfortunately the bar magnet was not strong enough to hold the blank in place during grinding, resulting in poor grinding tolerances. As a result, subsequent grinding experiments took place using the magnetic chuck already in place on the Chevalier grinding machine.

Two foil specimens were ground with flat type diamond wheels to determine the tolerances that could be attained. The first foil specimen was ground with a 320-grit flat diamond grinding wheel and was ground to a 0.01500 -in. nominal thickness. After taking approximately six to ten measurements across the foil specimen with a Mitutoyo digital micrometer, actual thickness dimensions ranged from 0.01510 in. to $0.01520 \mathrm{in}$. The next foil specimen was ground using a 120-grit flat diamond grinding wheel and was ground to a 0.01600 in. nominal thickness with actual dimensions ranging from $0.01585 \mathrm{in}$. to $0.01600 \mathrm{in}$. 


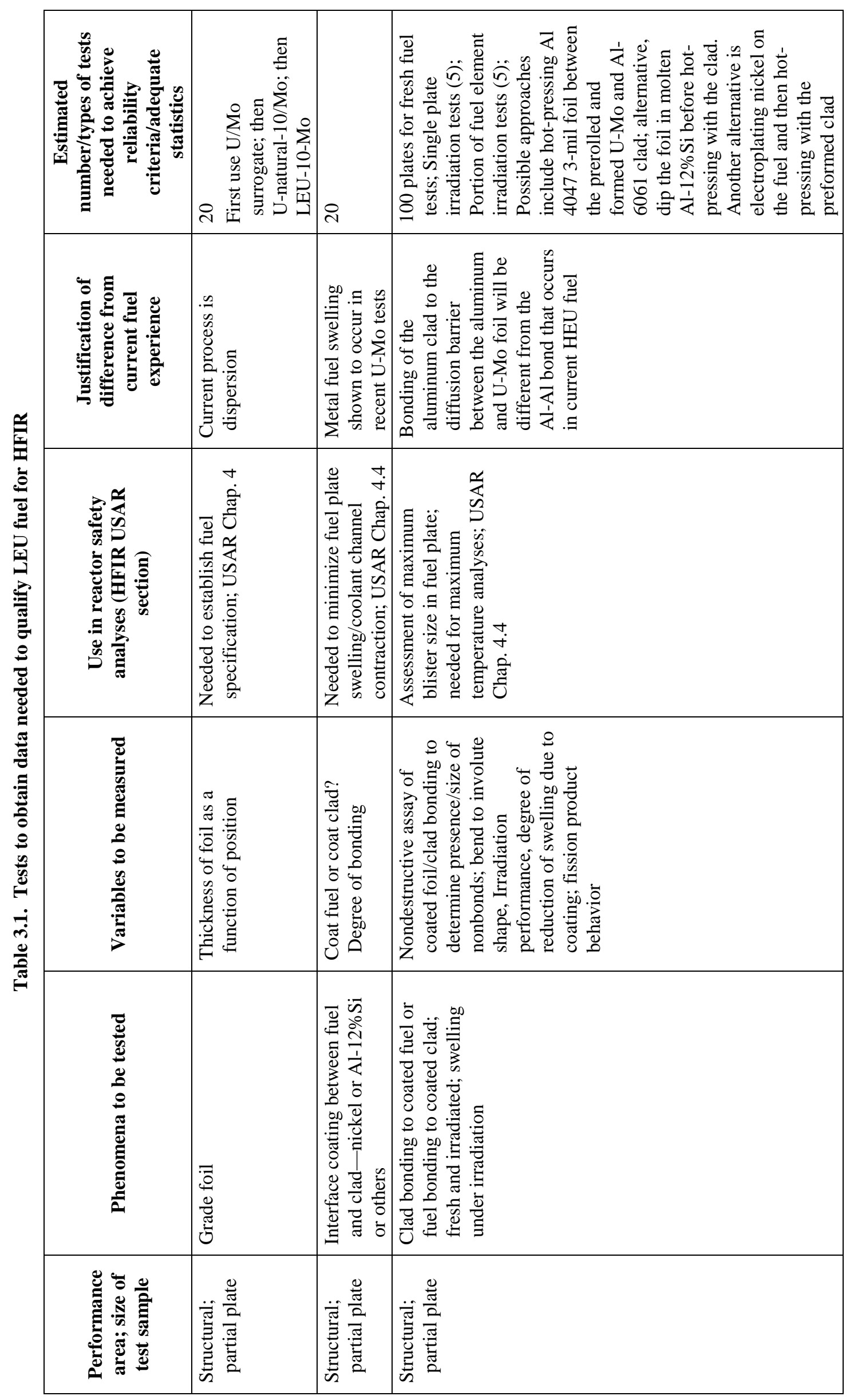




\begin{tabular}{|c|c|c|c|c|}
\hline 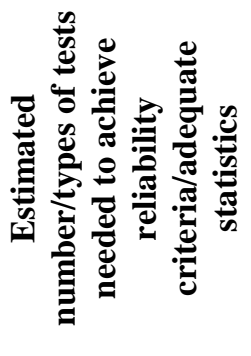 & $ㅇ$ & సి & 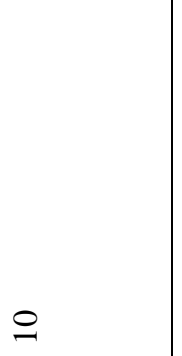 & 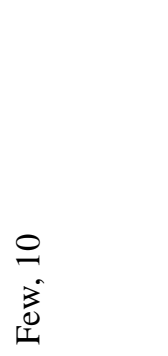 \\
\hline 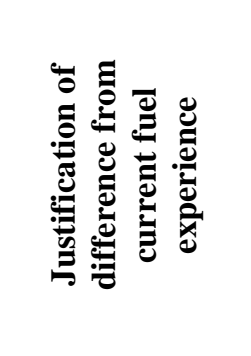 & 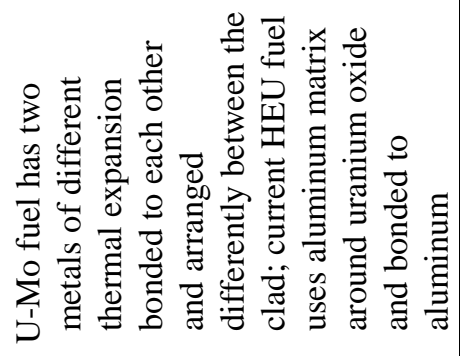 & 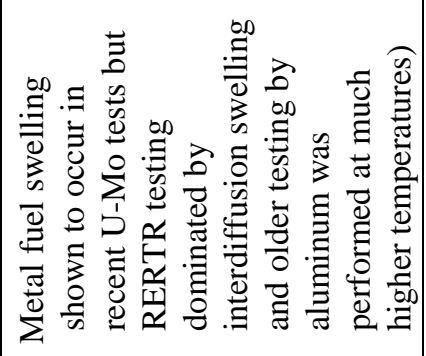 & 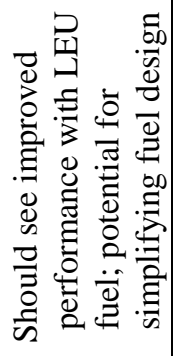 & 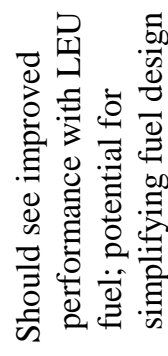 \\
\hline 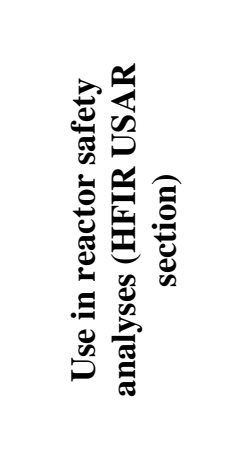 & 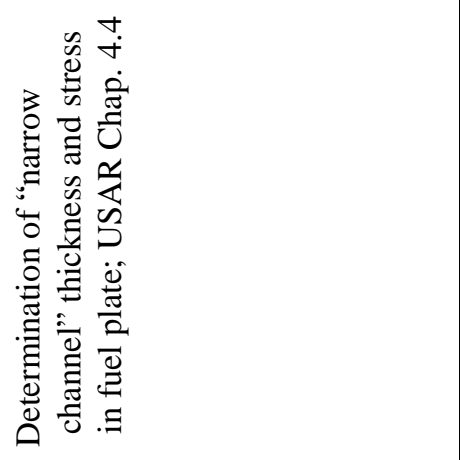 & 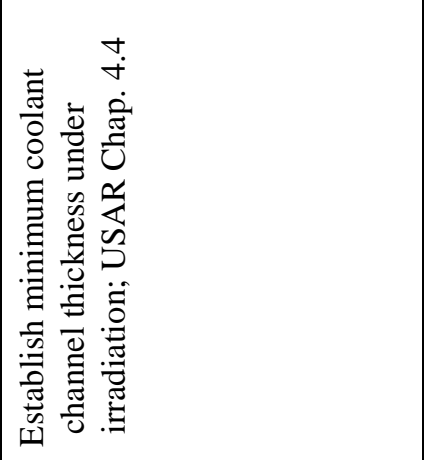 & 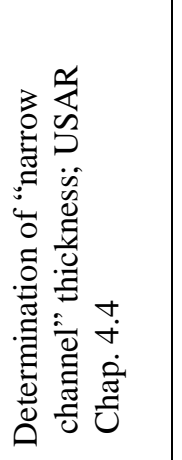 & 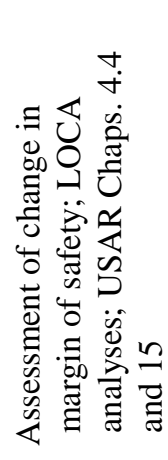 \\
\hline 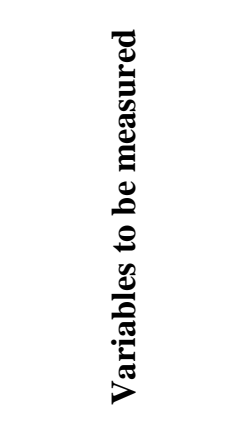 & 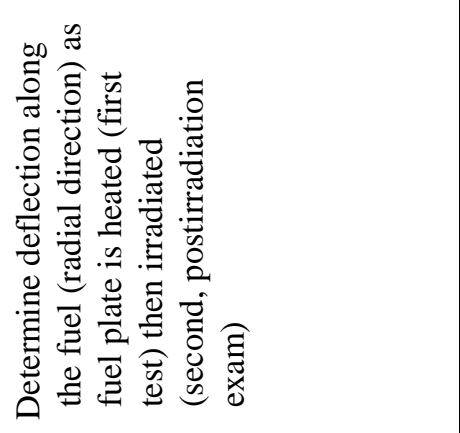 & 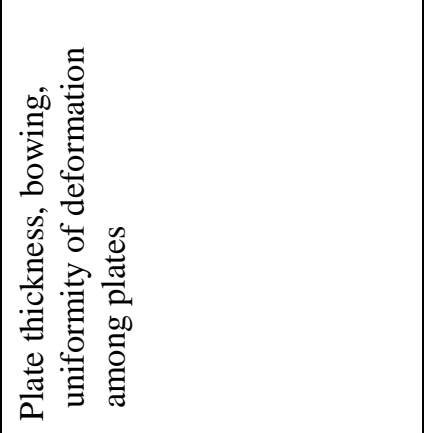 & 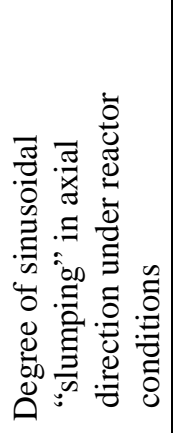 & 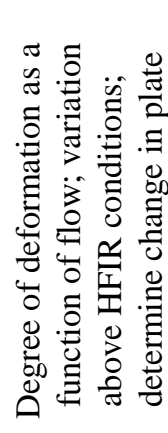 \\
\hline 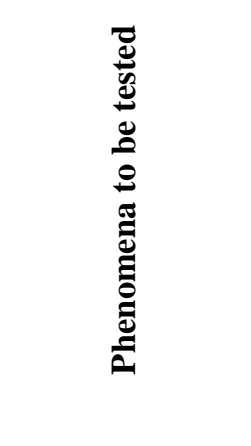 & 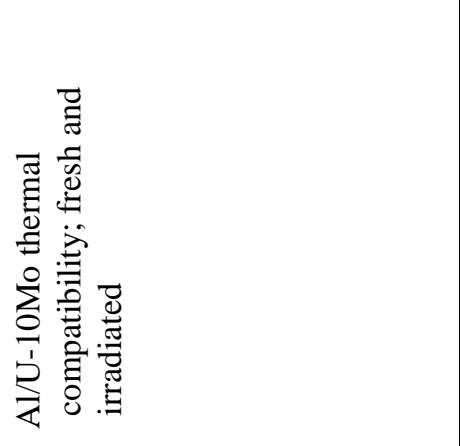 & 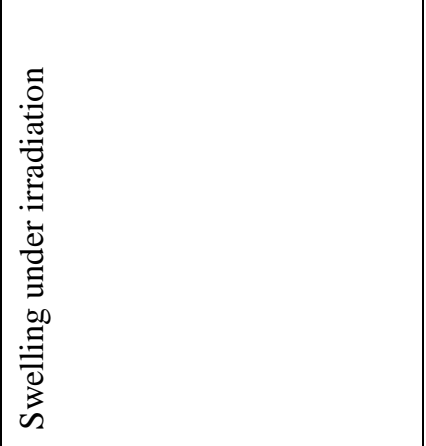 & 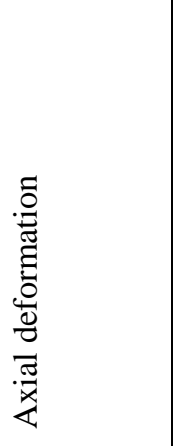 & 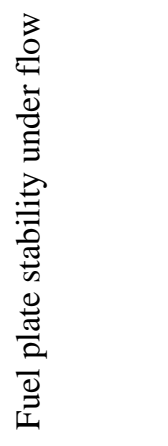 \\
\hline 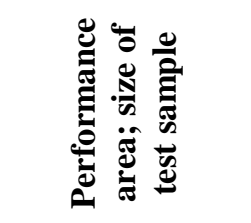 & 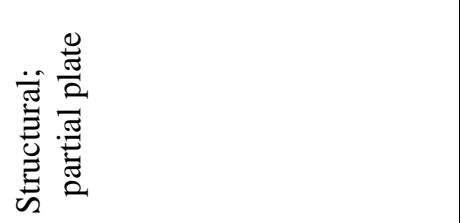 & 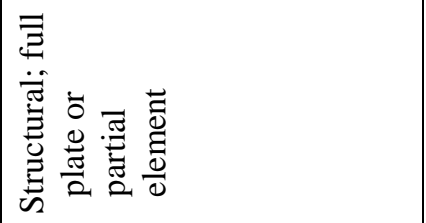 & 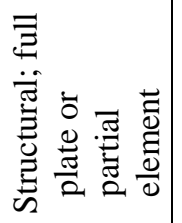 & 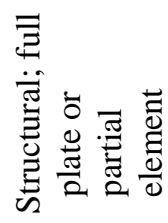 \\
\hline
\end{tabular}




\begin{tabular}{|c|c|c|c|}
\hline 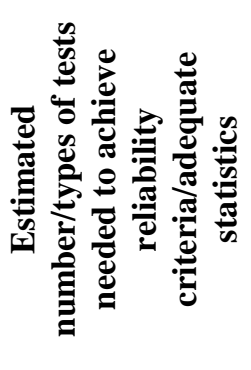 & 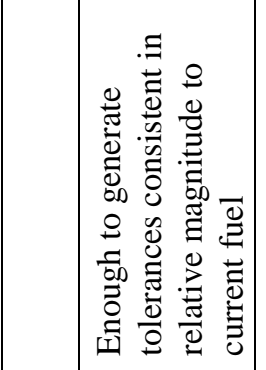 & 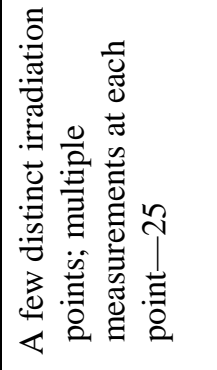 & તి \\
\hline 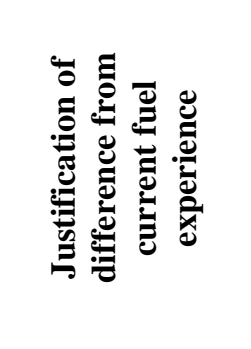 & 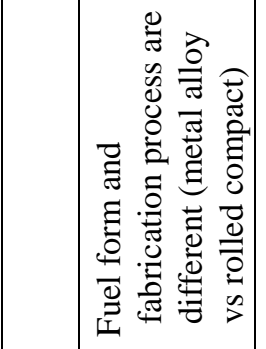 & 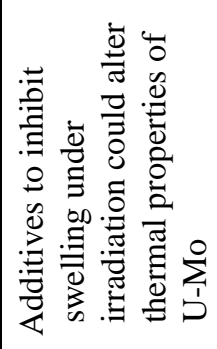 & 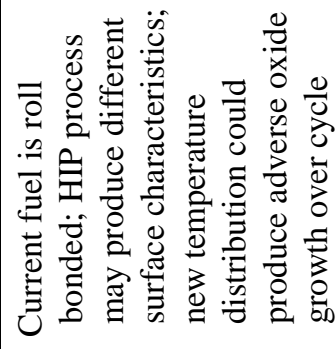 \\
\hline 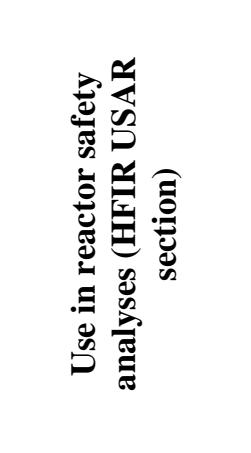 & 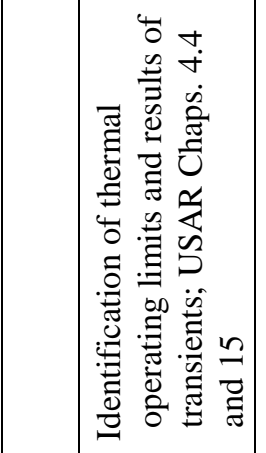 & 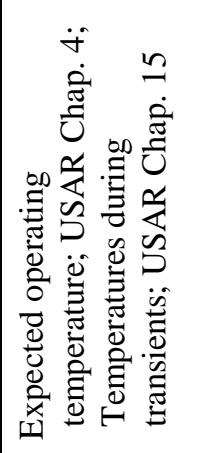 & 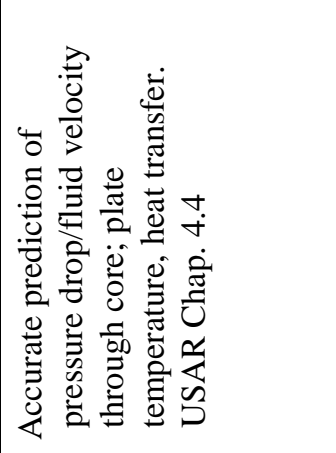 \\
\hline 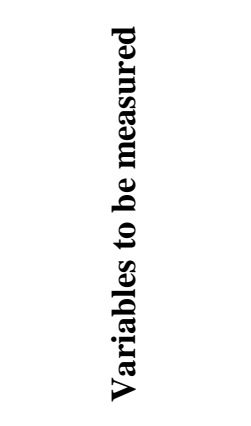 & 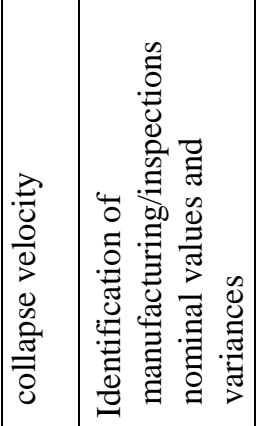 & 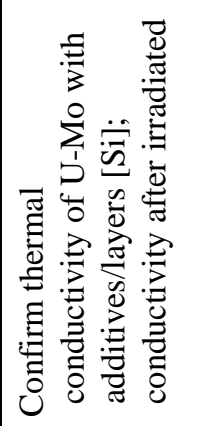 & 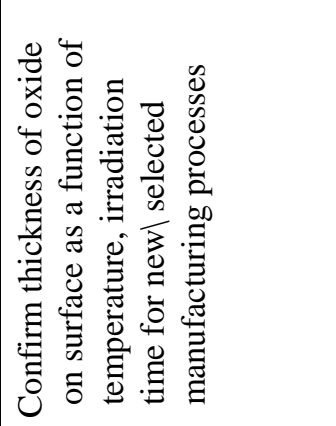 \\
\hline 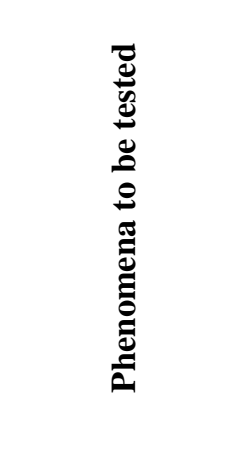 & 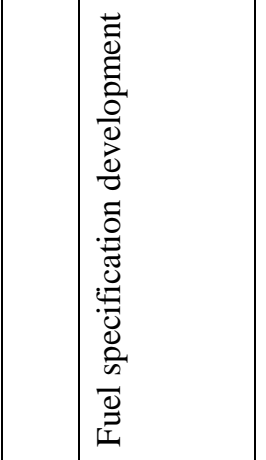 & 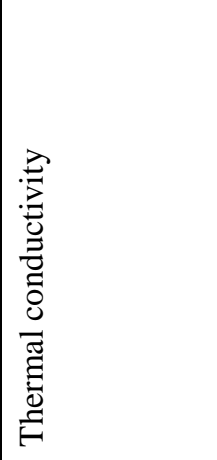 & 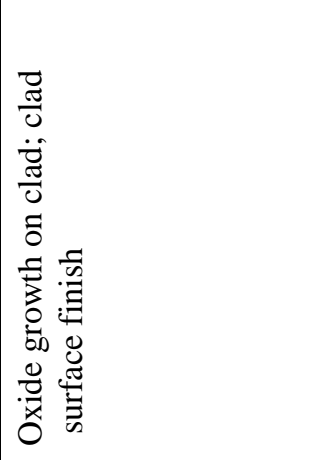 \\
\hline 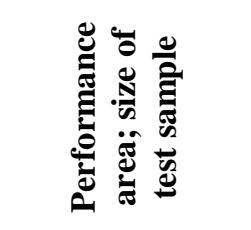 & 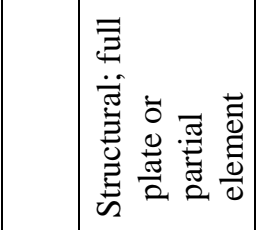 & 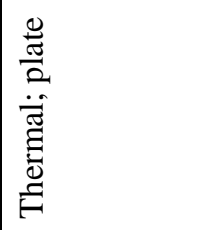 & 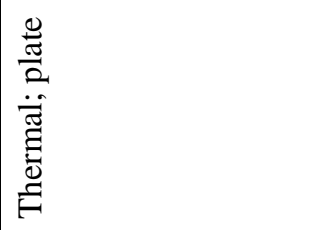 \\
\hline
\end{tabular}




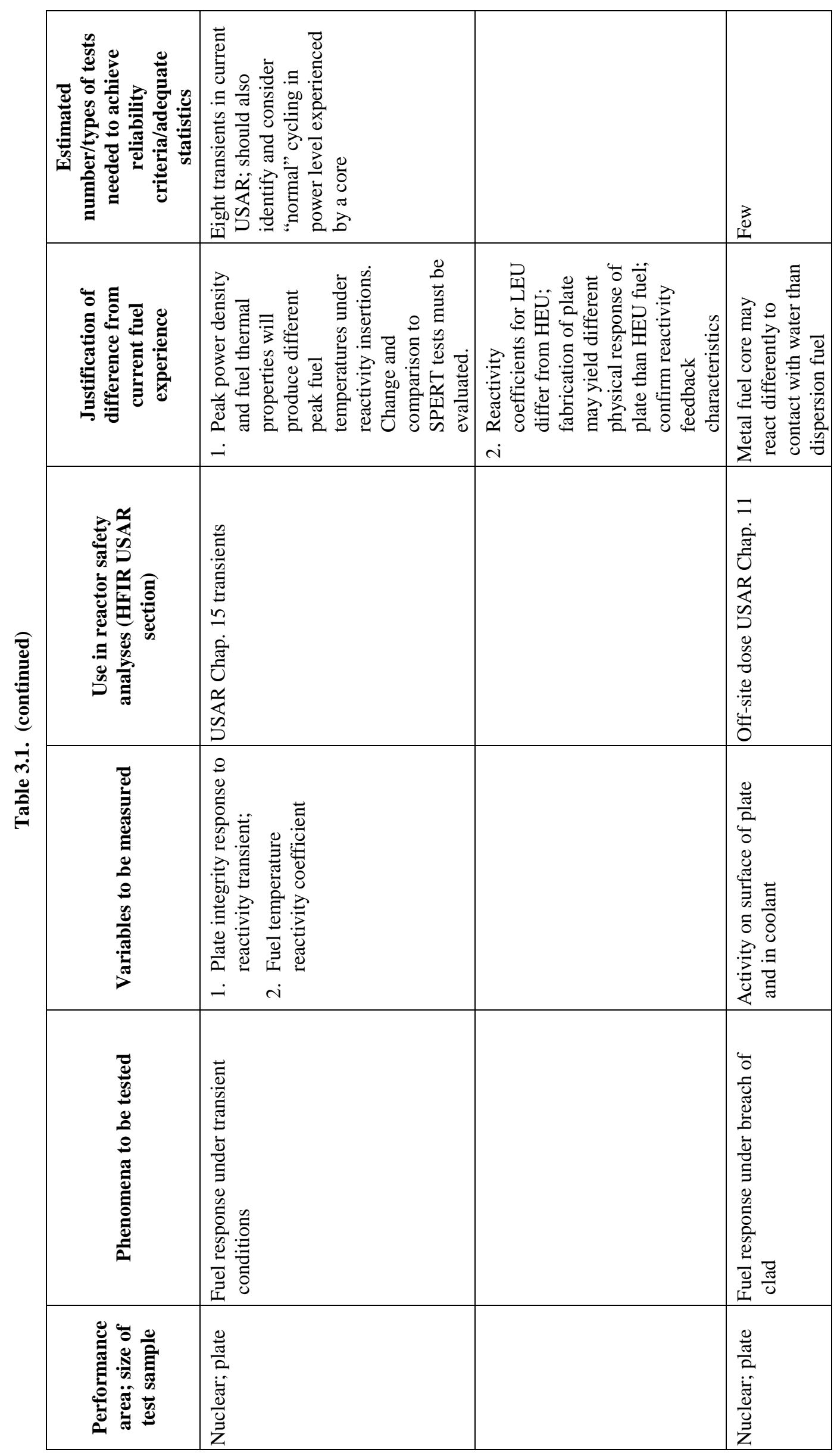




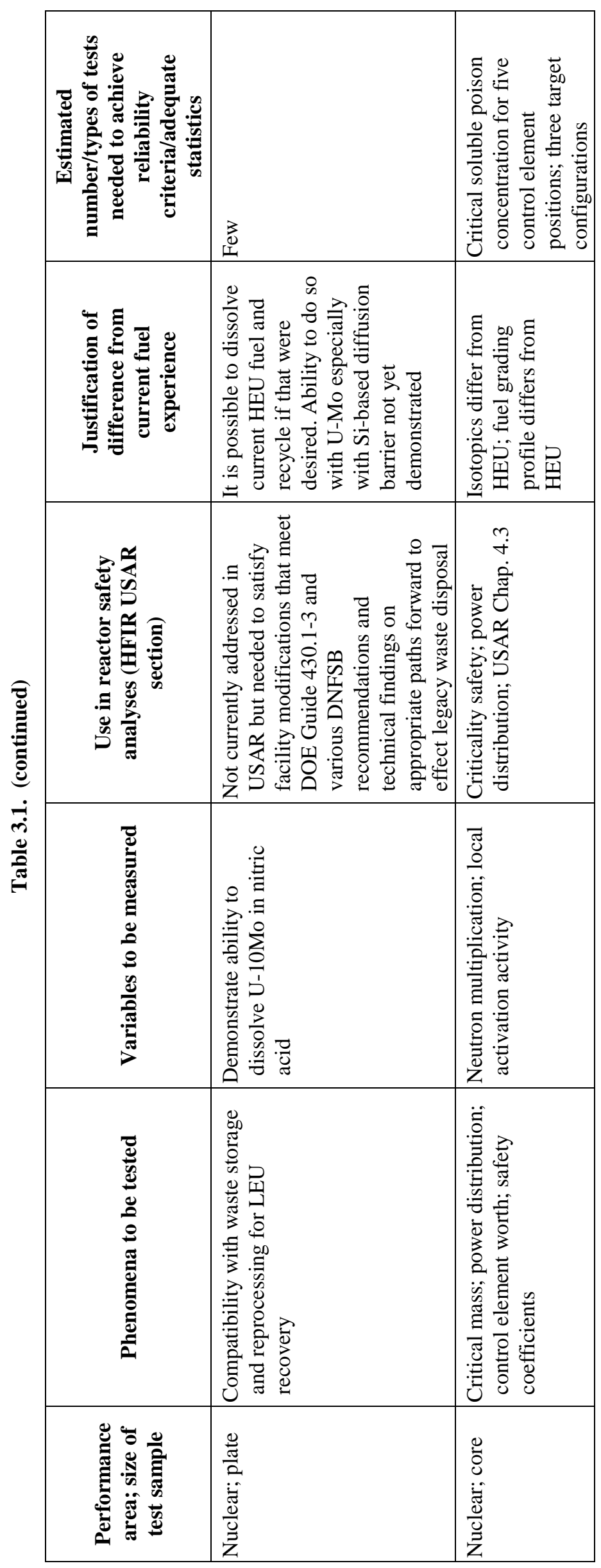




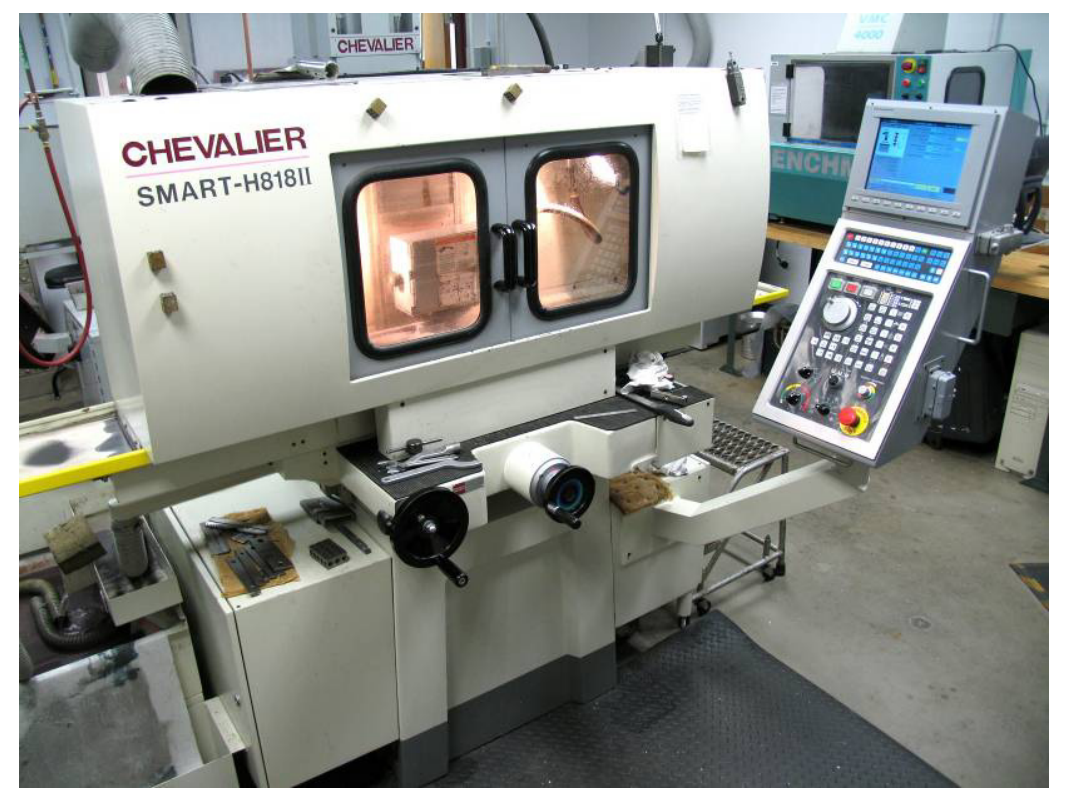

Fig. 3.1. Chevalier CNC surface grinder.

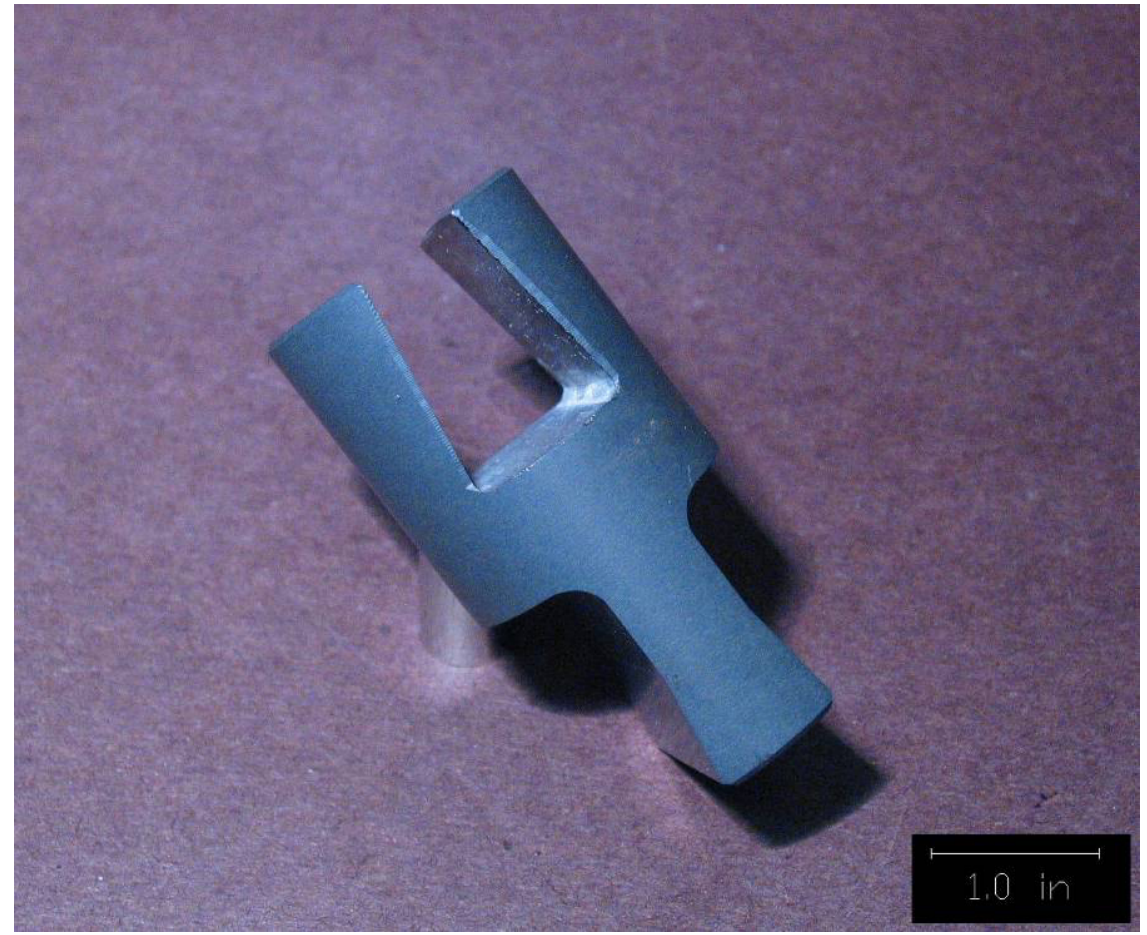

Fig. 3.2. Silicon carbide high-temperature tensile test grip. 


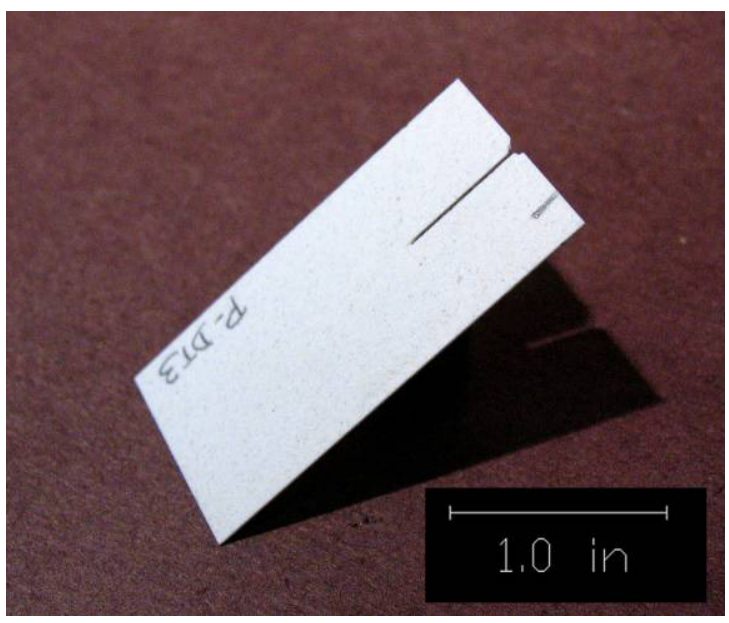

Fig. 3.3. Cordierite fracture toughness specimen.

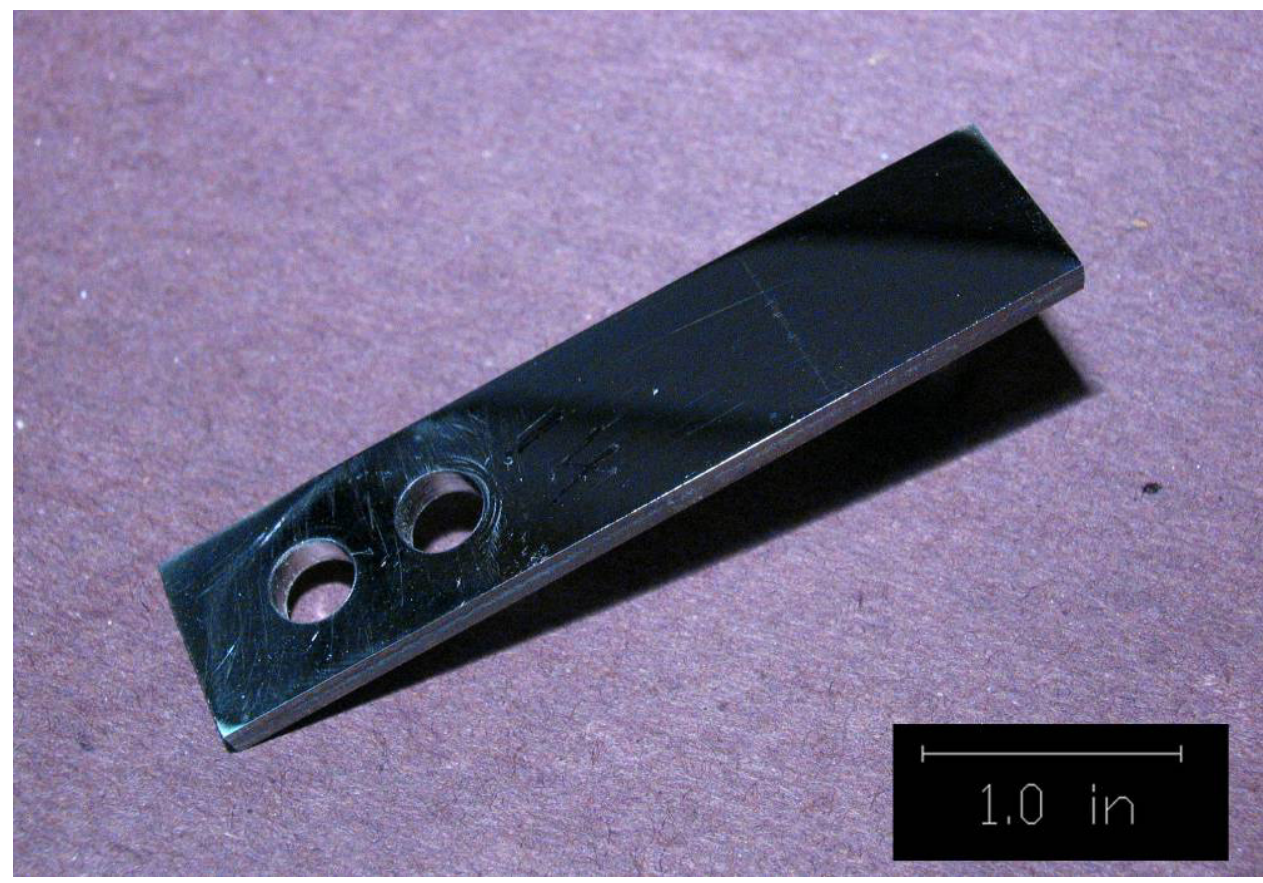

Fig. 3.4. Ti-6-4 fretting specimen. 


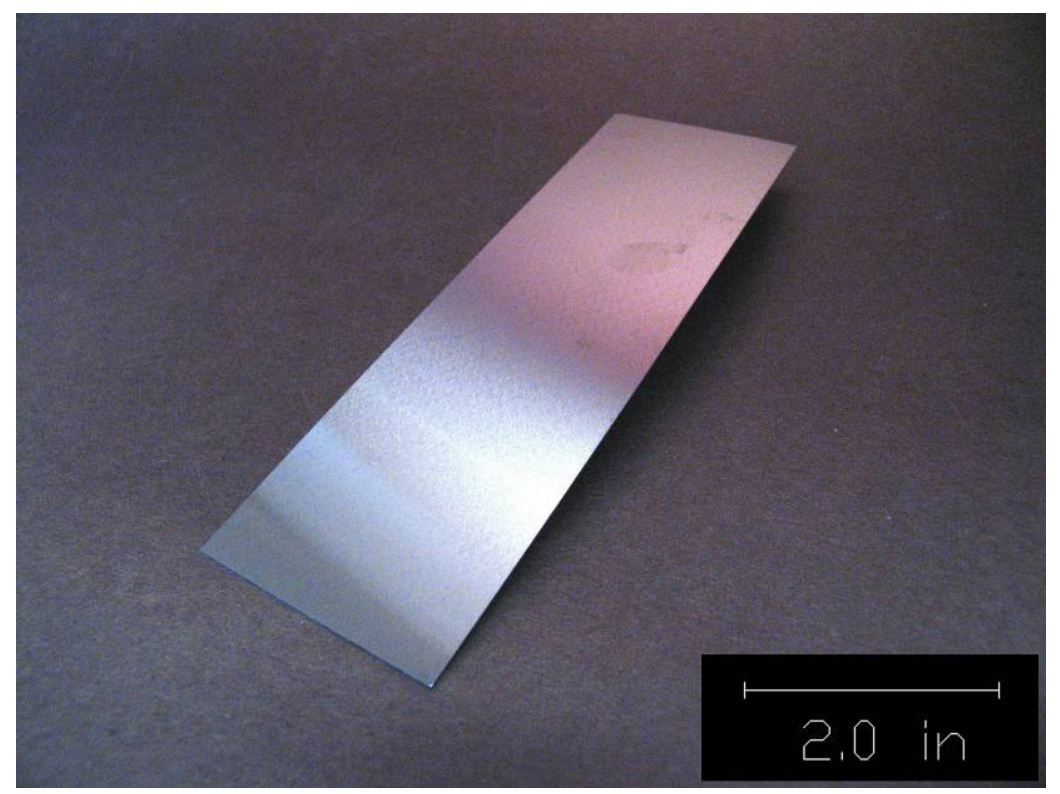

Fig. 3.5. Example of the surrogate foil specimen after grinding.

After the experiments using the flat type grinding wheels were done, two more foil specimens were ground using a 120-grit diamond wheel having a 0.049-in. radius. A radius type grinding wheel will be necessary when the profile to be ground requires an angular tool path (contoured fuel foil). As mentioned previously, the grinding wheel used in these initial experiments had a radius of 0.049 in. (the only wheel available at the time). This small radius is not ideal due to the potentially higher grinding stresses associated with the smaller wheel contact area. This higher grinding stress caused the foil to bow during grinding and become partially dislodged from the magnetic chuck. This bowing phenomenon resulted in large thickness variations. Up to a 0.0025 -in. difference was measured across the width of the bowed foil specimen. A larger radius type grinding wheel will be procured and used in the future to help reduce the bowing problem.

The radius tool tests were useful to help establish the feed rate necessary to produce a smooth finish. Two different feed rates were tried on the foil specimens ground with the radius type wheel. One was ground with a 0.25 -in./min cross feed rate and one was ground with a 0.125 -in./min cross feed rate. After grinding was complete on all four foil specimens, surface roughness data were gathered using a Taylor Hobson profilometer. The two roughness parameters measured were Ra, which is the arithmetic mean of the absolute departures of the roughness profile from the mean line, and $\mathrm{Rz}$, which is the numerically average height difference between the five highest peaks and five lowest valleys. A comparison of surface finish between all four foil specimens and the as-received shim stock material (presumably and rolled surface) can be seen in Table 3.2.

Table 3.2. Comparison of surface roughness data for ground and as-received surrogate fuel foil samples

\begin{tabular}{lcc}
\hline \multicolumn{1}{c}{ Wheel type } & $\begin{array}{c}\mathbf{R a} \\
(\boldsymbol{\mu \mathbf { m } )}\end{array}$ & $\begin{array}{c}\mathbf{R z} \\
(\boldsymbol{\mu \mathbf { m } )})\end{array}$ \\
\hline 320-grit flat & 0.334 & 2.519 \\
120-grit flat & 0.597 & 4.295 \\
Radius $0.25 \mathrm{in} . / \mathrm{min}$ & 1.617 & 9.264 \\
Radius $0.125 \mathrm{in} / \mathrm{min}$ & 1.226 & 7.653 \\
Shim stock as-received & 0.830 & 4.800 \\
\hline
\end{tabular}


Results of the surrogate foil grinding study so far have been encouraging. With the flat type grinding wheel, good tolerances have been achieved, within 0.0002 -in. thickness variation across the entire foil plate. This value can be compared to a thickness variation of $0.0012 \mathrm{in}$. from the as-received shim stock material. Also, surface roughness was improved from grinding with the flat wheels of both grit sizes. With the use of an appropriately sized radius type grinding wheel not only should thickness consistency be improved over the current 0.049-in. radius wheel, but the surface finish is expected to improve as well. Once satisfactory results are achieved grinding the foil plates flat, work will progress to grinding the double taper profile required. Also, alternative methods of holding the work piece, such as a vacuum chuck, are being investigated. 



\section{OBSERVATIONS FROM STUDIES}

\subsection{REACTOR ANALYSES}

With an increase in reactor power to $100 \mathrm{MW}$, a high volume fraction U-7Mo-in-Al dispersion fuel could attain the same neutron flux performance as with the current, HEU fuel but materials considerations appear to preclude production and irradiation of such a fuel. A diffusion barrier would be required if aluminum is to be retained as the interstitial medium, and the additional volume required for this barrier would degrade performance. Attaining the high volume fraction (55 wt \%) of U-Mo assumed in the computational study while maintaining the current fuel plate acceptance level at the fuel manufacturer is unlikely. Substitution of a zirconium alloy for aluminum would significantly increase the weight of the fuel element, the cost of the fuel element, and introduce an as-yet untried manufacturing process.

Based on studies conducted to date, a monolithic U-10Mo foil is the choice of LEU fuel for HFIR. Preliminary calculations indicate that with a modest increase in reactor power, the flux performance of the reactor can be maintained at the current level. A linearly graded, radial fuel thickness profile is preferred to the arched profile currently used in HEU fuel because the LEU fuel medium is a metal alloy foil rather than a powder. Developments in analysis capability and nuclear data processing techniques are under way with the goal of verifying the preliminary calculations of LEU flux performance.

\subsection{FUELS DEVELOPMENT}

A conceptual study of the operational cost of an LEU fuel fabrication facility yielded the conclusion that the annual fuel cost to the HFIR would increase significantly from the current HEU fuel cycle. Though manufacturing can be accomplished with existing technology, several engineering proof-of-principle tests would be required.

The RERTR program is currently conducting a series of generic fuel qualification tests at the Advanced Test Reactor. A review of these tests and a review of the safety basis for the current HEU fuel cycle led to the identification of a set of HFIR-specific fuel qualification tests. Much additional study is required to formulate a HFIR-specific fuel qualification plan from this set. However, one such test—creating a graded fuel profile across a flat foil— has been initiated with promising results.

\subsection{STUDIES PLANNED BUT NOT PERFORMED}

One method of reducing the local power density at the axial edges of the reactor core would be to place boron in the end plates of the fuel. This concept was discussed with the fuel fabricator, and the opinion of the staff was that axial grading of the fuel was preferable (likely less expensive) than fabricating an aluminum clad frame in which there was no boron in the radial edges of the plate or in the clad over the fuel but boron was present in the end plate region. Such a clad configuration would require welding or joining different types of aluminum (borated and unborated) together for each of the 540 plates that compose a HFIR core. Consequently, borated end plate studies were deferred in favor of pursuing methods development tasks to improve the accuracy of calculated neutronics parameters at the edges of the two-dimensionally graded core.

A study of the cost of modifications to the HFIR site to allow for handling LEU fuel—briefly discussed in Ref. 2-was not performed due to uncertainty as to the location of the various components of the LEU manufacturing process that are described in Ref. 16. A major cost identified in Ref. 2 was the construction of an LEU storage facility at the HFIR site. Should DOE choose to construct an LEU fuel manufacturing facility in Oak Ridge, it might be more economical to locate the HFIR fresh fuel storage facility at the fuel manufacturing site. Currently fresh, HEU HFIR fuel is stored at the Y-12 facility. Further cost studies for HFIR modifications were deferred pending additional study of the fuel manufacturing facility. 



\section{RECOMMENDED STUDIES FOR FY 2008}

The proposed work in FY 2008 in the HFIR LEU conversion feasibility project will build upon and extend the results and scope of the studies presented in this document. The goal of the studies is to find a design that results in no degradation to the performance parameters for HFIR and to identify the cost and schedule at the HFIR site of implementing the design.

The reactor analysis effort is organized into three funded areas, and two areas that should be pursued if funding can be made available during the fiscal year. These five areas of study are shown in Table 5.1.

ORNL support to fuel development activities are itemized in Table 5.2. As requested from program management, ORNL can supply support to irradiations being conducted by the RERTR program in the Advanced Test Reactor (ATR; i.e., diffractometry measurements).

Table 5.1. Reactor analysis activities proposed for FY 2008

\begin{tabular}{|c|c|c|}
\hline Area of study & Task ID & Subtask description \\
\hline \multirow{3}{*}{$\begin{array}{l}\text { Reference U-10Mo } \\
\text { fuel design }\end{array}$} & Neutronics & $\begin{array}{l}\text { Determine reference, monolithic, 2-D grading } \\
\text { profile; steady-state parameters }\end{array}$ \\
\hline & & Transient analyses of reference design \\
\hline & Thermal hydraulics & $\begin{array}{l}\text { Use newly developed methodology to identify } \\
\text { safety margin for reference fuel design }\end{array}$ \\
\hline \multirow{4}{*}{$\begin{array}{l}\text { Methods/model } \\
\text { development }\end{array}$} & $\begin{array}{l}\text { Cross section processing and } \\
\text { deterministic methods completion }\end{array}$ & $\begin{array}{l}\text { Develop/examine 2-D SCALE “slab” model } \\
\text { Transport methods (ATTILA model) }\end{array}$ \\
\hline & MCNP model development & Update/make operational MCNP depletion model \\
\hline & $\begin{array}{l}\text { Multidimensional, steady state heat } \\
\text { transfer model; turbulent mixing, } \\
\text { incorporate diffusion barrier and } \\
\text { nonbond assumptions in thermal- } \\
\text { hydraulic model }\end{array}$ & Development of COMSOL based methodology \\
\hline & $\begin{array}{l}\text { Probabilistic combination of } \\
\text { uncertainties (if funding is } \\
\text { available) }\end{array}$ & $\begin{array}{l}\text { Review/update TASHA code developed under } \\
\text { Advanced Neutron Source Program }\end{array}$ \\
\hline Program management & & $\begin{array}{l}\text { Report preparation } \\
\text { Travel } \\
\text { Review committees }\end{array}$ \\
\hline $\begin{array}{l}\text { Preparation for } \\
\text { regulatory review (if } \\
\text { funding is available) }\end{array}$ & & $\begin{array}{l}\text { Research publications for LEU validation; } \\
\text { develop plan for LEU validation studies }\end{array}$ \\
\hline $\begin{array}{l}\text { Economic/ } \\
\text { engineering } \\
\text { assessment } \\
\text { (if funding is } \\
\text { available) }\end{array}$ & Conversion to $100 \mathrm{MW}$ & $\begin{array}{l}\text { Similar study as Chap. } 4 \text { of Ref. } 2 \text { but identifies } \\
\text { cost/schedule for increasing HFIR power so } \\
\text { performance meets/exceeds current value }\end{array}$ \\
\hline
\end{tabular}


Table 5.2. Fuels development activities proposed for FY 2008

\begin{tabular}{ll}
\hline \multicolumn{1}{c}{ Task name } & \multicolumn{1}{c}{ Comment } \\
\hline & $\begin{array}{l}\text { Continue grading profile studies with } \\
\text { grinding/machining methods. As requested by }\end{array}$ \\
DOE, collaboration with FRM reactor staff and & FRM fuel fabricator (CERCA/ARIVA) on \\
& processes for fabricating monolithic fuel \\
Development of HFIR-specific fuel qualification plan & Issue ORNL/TM by end of fiscal year \\
Fuels program management & $\begin{array}{l}\text { Includes support to review committees, meeting } \\
\text { attendance, travel, and report preparation }\end{array}$ \\
\hline
\end{tabular}




\section{REFERENCES}

1. R. T. Primm III, R. J. Ellis, J. C. Gehin, D. L. Moses, J. L. Binder, and N. Xoubi, Assumptions and Criteria for Performing a Feasibility Study of the Conversion of the High Flux Isotope Reactor Core to Use Low-Enriched Uranium Fuel, ORNL/TM-2005/269, Oak Ridge National Laboratory, February 2006.

2. R. T. Primm III, R. J. Ellis, J. C. Gehin, K. T. Clarno, K. A. Williams, and D. L. Moses, Design Study for a Low-Enriched Uranium Core for the High Flux Isotope Reactor, Annual Report for FY 2006, ORNL/TM-2006/136, November 2006.

3. ATTILA computer code Web page: http://www.radiative.com/software.htm.

4. D. L. Poston and H. R. Trellue, User's Manual, Version 2.0 for MONTEBURNS Version 1.0, Los Alamos National Laboratory, LA-UR-99-4999, September 1999.

5. R. J. Ellis, J. C. Gehin, G. Ilas, and R. T. Primm III, "Neutronics Feasibility Study for Conversion of the High Flux Isotope Reactor with LEU U-7Mo Dispersion Fuel," Transactions of 2007 ANS Annual Meeting, Boston, Massachusetts (June 24-28, 2007).

6. R. T. Primm III and R. J. Ellis, "Analysis of an LEU Fuel with Spatially dependent Thickness in Two Dimensions," RRFM 2007/IGORR 2007 Conference, Lyon, France (March 11-15, 2007), http://www.euronuclear.org/meetings/rrfm2007/transactions.htm

7. MCNP-A General Monte Carlo N-Particle Transport Code, Version 5, LA-CP-03-0245, Los Alamos National Laboratory, April 2003.

8. D. R. Vondy, T. B. Fowler, and G. W. Cunningham III, The Bold Venture Computation System for Nuclear Reactor Core Analysis, Version III, ORNL-5711, Oak Ridge National Laboratory, June 1981.

9. http://www.corrosionsource.com/handbook/periodic/40.htm

10. A. P. Olson, A Users Guide to the PARET/ANL V7.2 Code-Draft, Reduced Enrichment for Research and Test Reactor (RERTR) Program, Argonne National Laboratory, Argonne, Illinois, June 2006.

11. HFIR Updated Safety Analysis Report, ORNL/HFIR/USAR/2344, Rev. 5, Oak Ridge National Laboratory, Oak Ridge, Tennessee, May 2005.

12. C. Galvez Velit and R. T. Primm III, Partial Safety Analysis for a Reduced Uranium Enrichment Core for the High Flux Isotope Reactor, ORNL/TM-2007/226, Oak Ridge National Laboratory (publication expected February 2008).

13. SCALE: A Modular Code System for Performing Standardized Computer Analyses for Licensing Evaluations, ORNL/TM-2005/39, Version 5, Vols. I-III, Oak Ridge National Laboratory, Oak Ridge, Tennessee, April 2005. [Available from Radiation Safety Information Computational Center (RSICC) at Oak Ridge National Laboratory as CCC-725.]

14. N. Xoubi and R. T. Primm III, Modeling of the High Flux Isotope Reactor Cycle 400, ORNL/TM-2004/251, Oak Ridge National Laboratory, Oak Ridge, Tennessee, August 2005.

15. H. A. McLain, HFIR Fuel Element Steady State Heat Transfer Analysis, Revised Version, ORNL/TM-1904, Oak Ridge National Laboratory, Oak Ridge, Tennessee, December 1967 as appended by T. E. Cole, L. F. Parsly, and W. E. Thomas, Revisions to the HFIR Steady State Heat Transfer Analysis Code, ORNL/CF-85/68, April 7, 1986.

16. J. D. Sease, R. T. Primm III, and J. H. Miller, Conceptual Process for the Manufacture of Low-enriched Uranium/Molybdenum Fuel for the High Flux Isotope Reactor, ORNL/TM-2007/39, Oak Ridge National Laboratory, September 2007.

17. Personal communication from M. K. Meyer, RERTR Fuel Development and Qualification Plan, INL/EXT-05-01017, January 2006 (draft).

18. J. D. Sease, R. T. Primm III, and J. H. Miller, "Considerations in the Development of a Process to Manufacture Low-enriched Uranium Foil Fuel for the High Flux Isotope Reactor," 
Transactions of the 2007 RERTR Meeting, Prague, Czech Republic, September 23-27, 2007, http://www.rertr.anl.gov/

19. B. Gibbesch and G. Elsser, "Ultra High Vacuum Diffusion Bonded $\mathrm{Nb}-\mathrm{Al}_{2} \mathrm{O}_{3}$ and $\mathrm{Cu}-\mathrm{Al}_{2} \mathrm{O}_{3}$ Joints-The Role of Welding Temperature and Sputter Cleaning," Acta Metall. Mater. 40, Suppl., pp. S59-S66 (1992).

20. T. Suga, Y. Takahashi, L. H. Takagi, I. B. Gibbesch, and G. Elssner, "Structure of Al-Al and Al-Si ${ }_{3} \mathrm{~N}_{4}$ Interfaces Bonded at Room Temperature by Means of the Surface Activation Method," Acta Metall. Mater. 40, Suppl., pp. S133-SI37, 1992.

21. T. Akatsu, N. Hosoda, T. Suga, and M. Ruhle, "Atomic structure of Al/Al interface formed by surface activated bondin Akatsu g," Journal of Materials Science, 34, 4133-4139 (1999). 


\section{Appendix A. RATIO OF THERMAL FLUX, HEU-TO-LEU, AT HFIR COLD SOURCE LOCATION}

Computational methods based on the neutron diffusion theory VENTURE code for HFIR are used to predict thermal neutron flux values at the location of the HFIR cold source. Results of the calculations are presented in Table A.1. The thermal neutron flux at end-of-cycle for the LEU fuel cycle is $1.059\left(10^{15}\right)$ neutrons $/\left(\mathrm{cm}^{2} * \mathrm{~s}\right)$. The degradation in performance occurs rapidly, after approximately $2 \mathrm{~d}$ of operation. The rapid degradation results from the cold source being located at the reactor centerline. Partial shielding of the cold source by the tantalum region of the control elements occurs at the beginning-of-cycle but movement of the elements. These control elements act to shift reactor power toward the center of the reactor. Once withdrawn, the power distribution shifts toward the outside edge of the reactor, and the impact of the denser LEU fuel relative to the HEU fuel is manifested in the reduced flux at the cold source.

Table A.1. Thermal neutron fluxes at the HFIR cold source for an operating power of $85 \mathrm{MW}$

\begin{tabular}{cc}
\hline $\begin{array}{c}\text { Time } \\
(\mathbf{d})\end{array}$ & $\begin{array}{c}\text { Thermal flux ratio } \\
\text { (HEU/LEU) }\end{array}$ \\
\hline 0.000 & 1.057 \\
0.588 & 1.043 \\
1.780 & 1.080 \\
7.180 & 1.090 \\
14.120 & 1.097 \\
18.820 & 1.112 \\
21.180 & 1.113 \\
23.530 & 1.121 \\
26.000 & 1.124 \\
\hline
\end{tabular}



ORNL/TM-2007/45

\section{INTERNAL DISTRIBUTION}

1. S. T. Baker (bakerst@ornl.gov)

2. K. J. Beierschmitt (beierschmitt@ornl.gov)

3. J. L. Binder (binderjl@ornl.gov)

4. C. A. Blue (blueca@ornl.gov)

5. S. E. Burnette (burnettese@ornl.gov)

6. C. W. Coates (coatescw@ornl.gov)

7. B. S. Cowell (cowellbs@ornl.gov)

8. D. C. Christensen (christensend@ornl.gov)

9. R. A. Crone (cronera@ornl.gov)

10. R. J. Ellis (ellisrj@ornl.gov)

11. J. C. Gehin (gehinjc@ornl.gov)

12. G. Ilas (ilasg@ornl.gov)

13. J. H. Miller (millerjh2@ornl.gov)
14. L. J. Ott (ottlj@ornl.gov)

15. C. V.Parks (parkscv@ornl.gov)

16-18. R. T. Primm III (primmrtiii@ornl.gov)

19. R. R. Rawl (rawlrr@ornl.gov)

20. A. W. Riedy (riedyaw@ornl.gov)

21. J. E. Rushton (rushtonje@ornl.gov)

22. L. J. Satkowiak (satkowiaklj@ornl.gov)

23. J. D. Sease (seasejd@ornl.gov)

24. K. A. Smith (smithka@ornl.gov)

25. R. L. Snipes (snipesrl@ornl.gov)

26. C. C. Southmayd (southmaydcc@ornl.gov)

27. S. J.Zinkle (zinklesj@ornl.gov)

28. ORNL Laboratory Records (hamrindr@ornl.gov)

\section{EXTERNAL DISTRIBUTION}

29. A. Adams, U.S. Nuclear Regulatory Commission, One White Flint North, 11555 Rockville Pike, Rockville, Maryland 20852-2738 (axa@nrc.gov)

30. T. Andes, BWXT/Y-12, Y-12 National Security Complex, P.O. Box 2009, Oak Ridge, TN 37831-8245 (andestc@y12.doe.gov)

31. R. A. Butler, Director, Research Reactor Center, 1513 Research Park Drive, Columbia, MO 65211 (ButlerRa@missouri.edu)

32. G. S. Chang, Idaho National Laboratory, P.O. Box 1625, Idaho Falls, ID 83415-3885 (gray.chang@inl.gov)

33. D. Chong, NA-212, U.S. Department of Energy, 1000 Independence Avenue SW, Washington, DC 20585 (Daniel.Chong@nnse.doe.gov)

34. H. E. Clark, U.S. Department of Energy Oak Ridge Office, P.O. Box 2001, Oak Ridge, TN 37831 (hkc@ornl.gov)

35. D. Diamond, Brookhaven National Laboratory, P.O. Box 5000, Upton, NY 11973-5000 (diamond@bnl.gov)

36. C. Galvez, 637 NW 14th Street, Corvallis, OR 97330 (galvezc@berkeley.edu)

37. H. D. Gougar, Manager, Fission \& Fusion Systems, INEEL, P.O. Box 1625, MS 3860, Idaho Falls, ID 83415-3860 (goughd@inl.gov)

38. M. Hassler, BWXT/Y-12, Y-12 National Security Complex, P.O. Box 2009, Oak Ridge, TN 37831-8245 (hasslerme@y12.doe.gov)

39. M. Hutmaker, U.S. Department of Energy, 1000 Independence Avenue SW, Washington, DC 20585 (matthew.hutmaker@nuclear.energy.gov)

40. D. Kutikkad, Assistant Reactor Manager-Physics, University of Missouri Research Reactor Facility, Columbia, MO 65211 (kutikkadk@missouri.edu)

41. J. Matos, Argonne National Laboratory, 9700 S. Cass Avenue, Argonne, IL 60439 (jim.matos@anl.gov)

42. C. McKibben, University of Missouri Research Reactor Facility, Columbia, MO 65211 (mckibben@missouri.edu)

43. D. M. Meyer, Idaho National Laboratory, P.O. Box 1625, Idaho Falls, ID 83415-3750 (Dana.Meyer@inl.gov)

44. T. Newton, MIT Nuclear Reactor Laboratory, 138 Albany St., Cambridge, MA 02139 (tnewton@mit.edu) 
45. W. Richards, NIST Center for Neutron Research, 100 Bureau Drive, Stop 8561, Gaithersburg, MD 208998561 (wade.richards@nist.gov)

46. W. C. Richardson, BWXT Technology, Inc., 2016 Mount Athos Rd., Lynchburg, VA 24504 (WCRichardson@bwxt.com)

47. J. Roglans, Argonne National Laboratory, 9700 S. Cass Avenue, Argonne, IL 60439 (roglans@anl.gov)

48. J. Snelgrove, Argonne National Laboratory, 9700 S. Cass Avenue, Argonne, IL 60439 (jimsnelgrove@anl.gov)

49. P. Staples, NA-212, U.S. Department of Energy, 1000 Independence Avenue SW, Washington, DC 20585 (Parrish.Staples@nnsa.doe.gov)

50. Daniel M. Wachs, MFC 791 B-147, Idaho National Laboratory, P.O. Box 6188, Idaho Falls, ID 83415 (Daniel.Wachs@inl.gov)

51. R. E. Williams, NIST Center for Neutron Research, 100 Bureau Drive, Stop 8560, Gaithersburg, MD 20899-8560 (robert.williams@nist.gov) 